\title{
A new basal ornithopod dinosaur from the Lower Cretaceous of China
}

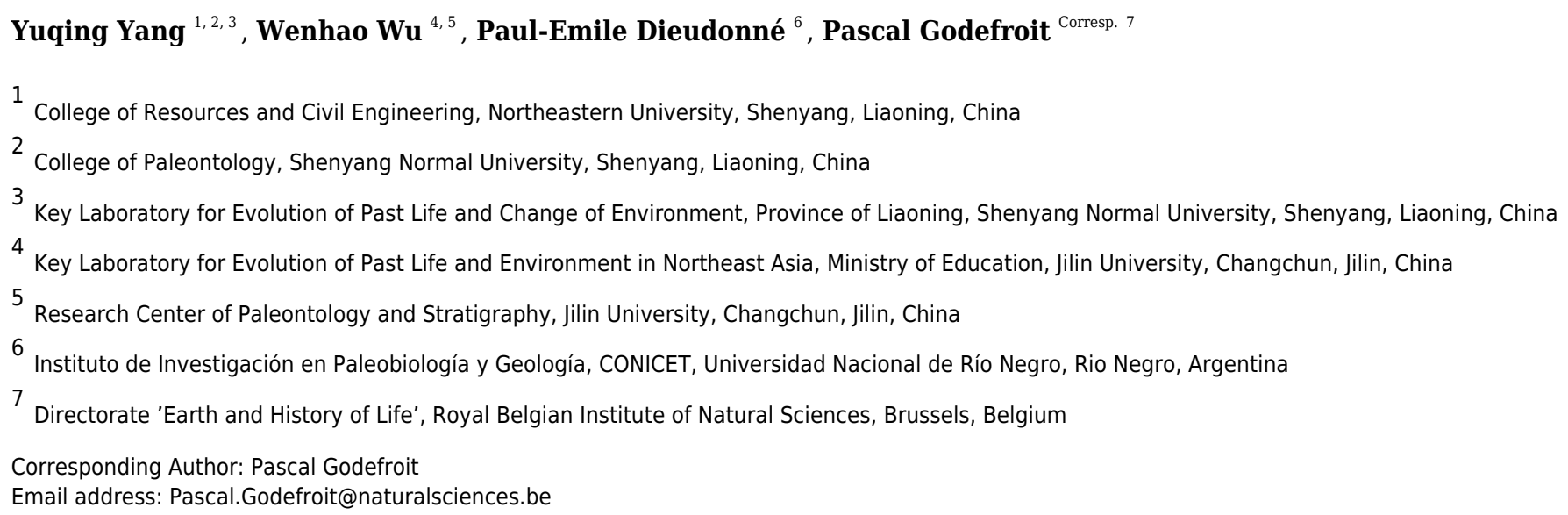

A new basal ornithopod dinosaur, based on two nearly complete articulated skeletons, is reported from the Lujiatun Beds (Yixian Fm, Lower Cretaceous) of western Liaoning Province (China). Some of the diagnostic features of Changmiania liaoningensis nov. gen., nov. sp. are tentatively interpreted as adaptations to a fossorial behavior, including: fused premaxillae; nasal laterally expanded, overhanging the maxilla; shortened neck formed by only six cervical vertebrae; neural spines of the sacral vertebrae completely fused together, forming a craniocaudally-elongated continuous bar; fused scapulocoracoid with prominent scapular spine; and paired ilia symmetrically inclined dorsomedially, partially covering the sacrum in dorsal view. A phylogenetic analysis places Changmiania liaoningensis as the most basal ornithopod dinosaur described so far. It is tentatively hypothesized that both Changmiania liaoningensis specimens were suddenly entrapped in a collapsed underground burrow while they were resting, which would explain their perfect lifelike postures and the complete absence of weathering and scavenging traces. However, further behavioural inference remains problematic, because those specimens lack extensive sedimentological and taphonomic data, as it is also the case for most specimens collected in the Lujiatun Beds so far. 
1 A new basal ornithopod dinosaur from the 2 Lower Cretaceous of China

3

4 Yang Yuqing ${ }^{1-3}$, Wu Wenhao ${ }^{4-5}$, Paul-Emile Dieudonné 6 , and Pascal Godefroit ${ }^{7}$

5 1. College of Resources and Civil Engineering, Northeastern University, Shenyang, Liaoning, China

6 2. College of Paleontology, Shenyang Normal University, Shenyang, Liaoning, China

7 3. Key Laboratory for Evolution of Past Life and Change of Environment, Province of Liaoning, Shenyang Normal

8 University, Shenyang, Liaoning, China

94 Key Laboratory for Evolution of Past Life and Environment in Northeast Asia, Ministry of Education, Jilin

10 University, Changchun, Jilin, China

11 5. Research Center of Paleontology and Stratigraphy, Jilin University, Changchun, Jilin, China

6. CONICET, Instituto de Investigación en Paleobiología y Geología, Universidad Nacional de Río Negro, Rio Negro, Argentina

7. Directorate 'Earth \& History of Life', Royal Belgian Institute of Natural Sciences, Brussels, Belgium

Corresponding author:

Pascal Godefroit

Email address: Pascal.Godefroit@naturalsciences.be 
19

20

\section{Abstract}

A new basal ornithopod dinosaur, based on two nearly complete articulated skeletons, is reported from the Lujiatun Beds (Yixian Fm, Lower Cretaceous) of western Liaoning Province (China). Some of the diagnostic features of Changmiania liaoningensis nov. gen., nov. sp. are tentatively interpreted as adaptations to a fossorial behavior, including: fused premaxillae; nasal laterally expanded, overhanging the maxilla; shortened neck formed by only six cervical vertebrae; neural spines of the sacral vertebrae completely fused together, forming a craniocaudally-elongated continuous bar; fused scapulocoracoid with prominent scapular spine; and paired ilia symmetrically inclined dorsomedially, partially covering the sacrum in dorsal view. A phylogenetic analysis places Changmiania liaoningensis as the most basal ornithopod dinosaur described so far. It is tentatively hypothesized that both Changmiania liaoningensis specimens were suddenly entrapped in a collapsed underground burrow while they were resting, which would explain their perfect lifelike postures and the complete absence of weathering and scavenging traces. However, further behavioural inference remains problematic, because those specimens lack extensive sedimentological and taphonomic data, as it is also the case for most specimens collected in the Lujiatun Beds so far.

\section{Subjects Paleontology, Taxonomy}

Keywords Dinosauria, Ornithopoda, Lower Cretaceous, Yixian Formation, Liaoning Province

\section{Introduction}

The Lujiatun Beds of the Yixian Formation are the lowermost fossil-bearing horizon of the Jehol Group in western Liaoning Province, China (He et al., 2006). Thousands of perfectly preserved vertebrate fossils have been unearthed from this horizon, including lizards, mammals and dinosaurs. Unlike in other horizons from the Jehol Biota, the Lujiatun fossils are preserved in three dimensions, revealing unique behaviour information, such as parental care (Meng et al., 2004) and sleeping posture (Xu and Norell, 2004) of dinosaurs, and mammals eating dinosaurs (Hu et al., 2005). Those fossils are preserved in 5 to 20-meter-thick tuffs exposed close to the Lujiatun Village, Shanyuan, Beipiao City. ${ }^{40} \mathrm{Ar} /{ }^{39} \mathrm{Ar}$ dating of ash from the Lujiatun beds interbedded with the fossiliferous layers shows that the Lujiatun specimens are Barremian (123.2 $\pm 1.0 \mathrm{Ma}$ ) in age (He et al., 2006). It has been hypothesized that the Lujiatun fauna was killed catastrophically by lahar from a nearby shield volcano (He et al., 2006; Zhao et al., 2007). A wide variety of theropod dinosaurs has been discovered in the Lujiatun Beds, including the tyrannosauroid 
Dilong paradoxus (Xu et al., 2004), the oviraptorosaur Incisivosaurus gauthieri (Xu et al., 2002a), the ornithomimosaurs Shenzhousaurus orientalis (Ji et al., 2003) and Hexing qingyi (Jin et al., 2012), the dromaeosaurid Graciliraptor lujiatunensis (Xu \& Wang, 2004a), and the troodontids Sinovenator changii (Xu et al., 2002b), Mei long (Xu \& Norell, 2004), Sinusonasus magnodens (Xu \& Wang, 2004b), Daliansaurus liaoningensis (Shen et al., 2017), and Liaoningvenator curriei (Shen et al., 2017). Among ornithischians, psittacosaurs are extremely abundant, being represented by the species Psittacosaurus lujiatunensis (including P. major and Hongshanosaurus houi; Hedrick \& Dodson, 2013). The neoceratopsian Liaoceratops yanzigouensis (Xu et al., 2002a) and the ornithopod Jeholosaurus shangyuensis (Xu et al., 2000) complete the dinosaur fauna.

Here we describe a new ornithischian dinosaur from the Lujiatun Beds, represented by two nearly complete and articulated specimens housed in the Paleontological Museum of Liaoning (PMOL) in Shenyang. Although it superficially resembles Jeholosaurus, represented by numerous specimens in the same deposits, the observed differences suggest that this new taxon occupies a more basal phylogenetic position at the base of the clade Ornithopoda.

\section{Material and Methods}

\section{Origin of the studied specimens:}

As it is the case for most of the dinosaur specimens known from western Liaoning Province, the holotype and referred specimens of Changmiania liaoningensis were acquired by the PMOL from local farmers, according to whom the specimens were collected in the Lujiatun Beds close to Lujiatun Village. The specimens were only partially prepared when they were acquired by the PMOL. PMOL AD00114 was subsequently carefully prepared by the PMOL technical staff. Careful examination by the authors of the present paper and X-ray analyses did not reveal any trace of forgery besides the usual restorations: some of the bones that have been slightly broken off or damaged during the preparation process have been glued together, and too fragilized fragments of bones have been cemented, but strictly following the original contour of the bone before restoration. The anatomy of the two specimen is fully concordant and clearly different from the Jeholosaurus specimens described from the same formation. Moreover, the morphological and phylogenetic information collected from the studied specimens is not discordant with our current understanding of basal ornithopod anatomy and evolution. Based on our close examination of the blocks and our previously accumulated rich experience with Liaoning specimens, we can therefore confidently guarantee the authenticity of the specimens. 
83

84

85

86

87

88

89

90

91

92

93

94

95

96

97

98

99

100

101

102

103

104

105

106

107

108

109

110

111

112

113

\section{Phylogenetic nomenclature:}

For consistency purpose, we have tried to comply as far as possible with the phylogenetic nomenclature adopted by Butler et al. (2008) and Boyd (2015) in some of the most recent revisions of ornithischian phylogeny. We therefore use the following definitions of higher-level ornithischian taxa in the present paper:

- Cerapoda Sereno, 1986: Parasaurolophus walkeri, Triceratops horridus, their most recent common ancestor and all descendants (Butler et al., 2008);

- Clypeodonta Norman, 2015: Hypsilophodon foxii, Edmontosaurus regalis, their most recent common ancestor, and all of its descendants (Norman, 2015);

- Genasauria Sereno, 1986: Ankylosaurus magniventris, Stegosaurus stenops, Parasaurolophus walkeri, Triceratops horridus, Pachycephalosaurus wyomingensis, their most recent common ancestor and all descendants (Butler et al., 2008).

- Heterodontosauridae Romer, 1966: all ornithischians more closely related to Heterodontosaurus tucki than to Parasaurolophus walkeri, Pachycephalosaurus wyomingensis, Triceratops horridus, or Ankylosaurus magniventris (Sereno, 2005);

- Iguanodontia Dollo, 1888: all ornithopods more closely related to Parasaurolophus walkeri than to Hypsilophodon foxii or Thescelosaurus neglectus (Sereno, 2005);

- Jeholosaurinae (Han et al., 2012): all ornithopods more closely related to Jeholosaurus shangyuanensis, than to Changmiania liaoningensis, Orodromeus makelai, Nanosaurus agilis, Hypsilophodon foxii, or Thescelosaurus neglectus (modified from Han et al., 2012);

- Marginocephalia Sereno, 1986: Triceratops horridus, Pachycephalosaurus wyomingensis, their most recent common ancestor and all descendants (Butler et al., 2008);

- Neornithischia Cooper, 1985: all genasaurians more closely related to Parasaurolophus walkeri than to Ankylosaurus magniventris or Stegosaurus stenops (Butler et al., 2008);

- Ornithischia Seeley, 1887: all dinosaurs more closely related to Triceratops horridus than to Passer domesticus or Saltasaurus loricatus (Butler et al., 2008);

- Ornithopoda Marsh, 1881: all genasaurians more closely related to Parasaurolophus walkeri than to Triceratops horridus (Butler et al., 2008);

- Orodrominae Brown et al., 2013: all ornithopods more closely related to Orodromeus makelai than to Nanosaurus agilis or Thescelosaurus neglectus (this study);

- Parksosaurinae Buchholz, 2002: all clypeodonts more closely related to Parksosaurus warreni

Peer] reviewing PDF | (2020:05:48592:1:1:NEW 31 Jul 2020) 
114

115

than to Thescelosaurus neglectus or Parasaurolophus walkeri (Boyd, 2015, modified);

- Thyreophora Nopcsa 1915: all genasaurians more closely related to Ankylosaurus magniventris than to Parasaurolophus walkeri, Triceratops horridus, or Pachycephalosaurus wyomingensis (Butler et al., 2008).

\section{Phylogenetic analysis:}

To assess its phylogenetic position within ornithischian dinosaurs, we included Changmiania liaoningensis in an extensively modified version of the character-taxon matrix published by Dieudonné et al. (2016). Besides Changmiania liaoningensis, we have integrated 14 taxa that were not included in Dieudonné et al. (2016) data-matrix: Ankylosauria, Archaeoceratops oshimai, Chaoyangsaurus youngi, Goyocephale lattimorei, Homalocephale calathocercos, Isaberrysaura mollensis, Kulindadromeus zabaikalicus, Laquintasaura venezuelae, Liaoceratops yanzigouensis, Morrosaurus antarcticus, Stegosauria, Stenopelix valdensis, Thescelosaurus assiniboiensis, and Wannanosaurus yansiensis. In the present analysis, we have not coded the basal ornithopod Oryctodromeus cubicularis, from the middle Cretaceous Blackleaf Formation of southwestern Montana and the Wayan Formation of southeastern Idaho, USA (Varricchio et al., 2007; Krumenacker, 2010, 2017), pending the formal publication of the numerous partial skeletons from the Wayan Formation (Krumenacker, 2010, 2017). The final analysis consequently includes 61 taxonomic units and 263 characters (Table S1 provides the character descriptions, Table S2 contains the final data matrix, Table S3, the data matrix in TNT format, and Table S4, the character support for selected nodes). Herrerasaurus ischigualastensis was used as outgroup. The analysis of the dataset was run using TNT (Tree Analysis using New Technology, Goloboff et al. 2008); all the characters were equally weighted and regarded as non-additive. Several characters were coded as additive (\#110, \#149, \#152, \#205, \#208) in the original matrix published by Dieudonné et al. (2016); however, we estimate that assessing whether a character is additive is in most cases rather subjective and, by experience, subject to discussions, depending on the final result we have in mind before running the analysis; to avoid any circular reasoning, we have therefore decided to regard all characters as non-additive in the present analysis. We performed a first round of 100 "New Technology" search analyses, with default parameter, and then explored the shortest tree islands found performing Tree Bisection Reconnection analyses saving all shortest tree found. Bremer nodal support was calculated in TNT saving all trees up to 10 steps longer than the most parsimonious results. 
144 Institutional abbreviations: BYU: Brigham Young University, Provo, Utah, U.S.A.; IGM: Institute of 145 Geology of Mongolia, Ulanbaatar, Mongolia; IVPP: Institute of Vertebrate Paleontology and 146 Paleoanthropology, Beijing, China; KDRC: Korea Dinosaur Research Center, Chonnam National University, 147 Gwanju, Republic of Korea; MOR: Museum of the Rockiens, Bozeman, Montana, U.S.A.; NHMUK: Natural 148 History Museum, London, U.K.; PMOL: Paleontological Museum of Liaoning, Shenyang, China; YPM: Yale 149 Peabody Museum of Natural History, New Haven, Connecticut, U.S.A.

150

151 Nomenclatural acts:

152 The electronic version of this article in Portable Document Format (PDF) will represent a published work 153 according to the International Commission on Zoological Nomenclature (ICZN), and hence the new names contained in the electronic version are effectively published under that Code from the electronic edition alone. This published work and the nomenclatural acts it contains have been registered in ZooBank, the online registration system for the ICZN. The ZooBank LSIDs (Life Science Identifiers) can be resolved and the associated information viewed through any standard web browser by appending the LSID to the prefix http://zoobank.org/. The LSID for this publication is: urn:Isid:zoobank.org:pub:9C5F2451-4E00-4919-9FE9-14E6629FCF64. The online version of this work is archived and available from the following digital repositories: PeerJ, PubMed Central and CLOCKSS.

\section{Systematic Paleontology}

Dinosauria Owen, 1842

Ornithischia Seeley, 1887

Neornithischia Cooper, 1985

Ornithopoda Marsh, 1881

Changmiania liaoningensis nov. gen., nov. sp.

Etymology - Changmian: eternal sleep, in Chinese Pinyin; liaoningensis: from Liaoning.

Holotype - PMOL AD00114, a nearly complete articulated skeleton (Figs. 1A and 1B)

Referred specimen - PMOL LFV022, another nearly complete skeleton, in dorsal view (Fig. 1C). 
175 Diagnosis (autapomorphies preceded by an asterisk): Fused premaxillae; nasal laterally expanded, 176 overhanging the maxilla; long and straight posterior process of supraorbital, nearly contacting the 177 postorbital; * rostrocaudally elongated frontals: maximum length to width ratio > 4; *no sagittal crest on 178 parietal; infratemporal fenestra triangular in lateral view, wider dorsally than ventrally; jugal process of 179 postorbital rostrocaudally narrow along its whole height; * rostral process of squamosal straight and 180 rostrocaudally elongated; *prominent caudal boss at the dorsolateral corner of the squamosal; *ventral border of dentary convex and ventral border of angular deeply concave, so that the lower jaw looks sigmoidal in lateral view; six cervical vertebrae; *neural spines of the sacral vertebrae completely fused together, forming a craniocaudally-elongated continuous bar; fused scapulocoracoid; *scapular blade asymmetrically expanded both ventrally and dorsally; *paired ilia symmetrically inclined dorsomedially, partially covering the sacrum in dorsal view; dorsal margin of ilium regularly convex along the whole length of the bone; *proximal half of fibula as robust as the corresponding portion of the tibia.

187

188

189

190

191

193

194

195

196

197

198

200

201

202

203

204

205

The osteological description of Changmiania liaoningensis proposed below is mainly based on its holotype PMOL AD00114, except when variation can be observed with referred specimen PMOL LFV022 or when some parts of the skeleton (e.g. the hands) are better exposed in the latter specimen. References to PMOL LFV022 are in those cases explicitely indicated in the text.

\section{Skull}

Premaxilla - The maxillary process of the premaxilla is particularly robust, trapezoidal in shape, and inclined both caudodorsally and dorsolaterally (Fig. 2). It forms the entire caudal margin of the external naris. It regularly expands rostrocaudally as it extends dorsally. Its caudal border contacts the maxilla and its straight dorsal border, the nasal. Its caudodorsal corner contacts the lacrimal, excluding the maxilla from the nasal, as also observed in Heterodontosaurus (Sereno, 2012), Kulindadromeus (Godefroit et al., 2014), and larger Jeholosaurus specimens (Barrett \& Han, 2009). The much smaller nasal process forms the rostrodorsal border of the external naris; as also observed in Jeholosaurus (Barrett \& Han, 2009), it only participates in the rostral third of the narial dorsal margin (Figs. 2). This process rapidly tapers both mediolaterally and dorsoventrally as it extends dorsally, terminating in a fine point, so that the external naris is highly constricted in dorsal view, at the level of the contact between 
206 the paired premaxillae and nasals (Figs. 3 and 4). The rostral end of the nasal slightly overlaps the caudal

207 end of the premaxilla. In dorsal view, the premaxillae are nearly completely fused together; only the 208 distal end of their nasal process is not fused. Extensive fusion of the premaxillae has been reported in 209 Changchunsaurus (Jin et al., 2010), Oryctodromeus and Zephyrosaurus, and interpreted as an adaptation 210 to burrowing behavior (Varricchio et al., 2007). The rostral surface of the paired premaxillae is rugose

211 (Fig. 5A), as also observed in Hypsilophodon (Galton 1974), Zephyrosaurus (Sues 1980), Jeholosaurus

212 (Barrett \& Han, 2009), and Changchunsaurus (Jin et al., 2010), and likely served for the attachment of a

213 rhamphotheca. The rugosities slightly overhang the rostroventral corner of the external naris. They

214 extend along the rostroventral surface of the main body of the premaxilla and potentially obscure the

215 presence of premaxillary foramina. Above those rugosities the lateral surface of the premaxilla is convex

216 and forms a shelf, so that the external naris is strongly inset from the lateral surface of the premaxilla

217 (Fig. 5A). It contrasts with the concave lateral surface of the premaxilla in Jeholosaurus (Barrett \& Han,

218 2009) and Changchunsaurus (Jin et al., 2010). There is no distinct external narial fossa, as observed in

219 some Jeholosaurus specimens (Barrett \& Han, 2009). The lateroventral border of the premaxilla lies as

220 about the same level as the ventral margin of the maxilla (Fig. 2), as also observed in Zephyrosaurus

221 (Sues, 1980, fig. 16), Orodromeus (Scheetz, 1999), Jeholosaurus (Barrett \& Han, 2009), Changchunsaurus

222 (Jin et al., 2010), and Haya (Makovicky et al., 2011).

223 The number of premaxillary teeth cannot be precisely evaluated. Nor is it possible to determine

224 if the first premaxillary tooth was located close to the rostral end of the premaxilla or if the rostral end

225 of the premaxilla was edentulous. The premaxillary teeth are robust, with a well-marked constriction

226 between the root and the crown (Fig. 5A). The crowns are clearly separated from each other as in other

227 basal cerapodans, including Hypsilophodon (Galton, 1974), Yinlong (Xu et al., 2006), Jeholosaurus

228 (Barrett \& Han, 2009), and Changchunsaurus (Jin et al., 2010). The crowns have a subconical shape, with 229 bulbous crown bases; they taper apically and are slightly recurved. They do not bear denticles and their 230 enamel is perfectly smooth.

231

232

Maxilla - On the rostral third of the maxilla, the ascending process is high and hook-like (Figs. 2 and 5B); its concave caudal border forms the rostral margin of the antorbital fenestra, whereas its straight rostral border contacts the premaxilla. The apex of the ascending process contacts the lacrimal. A small circular fossa is set rostrally at the base of the ascending process, at the junction with the premaxilla (Figs. 2 and 
238

239

240

241

242

243

244

245

246

247

248

249

250

251

252

253

254

255

256

257

258

259

260

261

262

263

264

265

266

267

268

269

2009), and was identified as a synapomorphy of Ornithopoda by Butler et al. (2008). The tooth-bearing ramus is rostrocaudally elongated and maintains an approximately even height along most of its length (Fig. 5B). A horizontal ridge extends rostrally from the ventral margin of the jugal and limits a wide and dorsoventrally concave buccal emargination (Figs. 5B and 5C). The distance between the horizontal ridge and the ventral margin of the external antorbital fenestra is significantly less than in Changchunsaurus (Jin et al., 2010), reflecting the larger size of the external antorbital fenestra. A horizontal series of small nutrient formina is present ventrally to the horizontal ridge (Fig. 5B). The dorsal portion of the medial lamina of the maxilla is visible within the antorbital fossa (Fig. 5B).

Fifteen maxillary teeth can be observed on the right maxilla of the holotype. A short edentulous diastema, equivalent to the mesiodistal length of 1 or 2 crowns, is present at the rostral end of the maxilla (Fig. 5B), as in Changchunsaurus (Jin et al., 2010). The size of the maxillary crowns progressively increases up to the mid-length of the maxilla. The crowns are poorly preserved and/or partly destroyed during preparation. As also observed in Changchunsaurus (Jin et al., 2010), the maxillary crowns are imbricated, the distal part of each crown overlaping laterally the mesial part of the succeeding one (Fig. 5C). The crowns are as high as mesiodistally long. Small denticles, supported by ridges extending from a weak basal cingulum, are developed along the apical half of the crowns; those ridges look better developed than in Jeholosaurus (Barrett \& Han, 2009) and Changchunsaurus (Jin et al. 2010), more closely resembling the condition in Hypsilophodon (Galton, 1974). The maxillary crowns of Orodromeus apparently lack ridges supporting their marginal denticles (Scheetz, 1999). A low median eminence is usually developed on the labial surface, but a prominent primary ridge is absent.

Lacrimal - As is usual in basal cerapodans, the lacrimal consists of a ventral and dorsal process forming an inverted ' $L$ ' in lateral view (Figs. 2 and 6A). Both processes form an angle of approximately 120 degrees, as in Jeholosaurus. The ventral process becomes more rostrocaudally restricted ventrally. This process separates the rostral margin of the orbit from the caudal margin of the antorbital fossa; it contacts ventrally the maxilla and the jugal. The dorsal process extends rostrally to contact the maxillary process of the premaxilla. Its dorsal border contacts the prefrontal and nasal; ventrally it participates in the apical margin of the antorbital fossa and it contacts the ascending process of the maxilla (Fig. 6A).

Nasal - In dorsal view, the paired nasals taper rostrally above the external nares, where they contact the fused premaxillae to form the internarial bar; they quickly expand laterally and overhang the maxilla (Fig. 3) as it is also observed, to a lesser degree, in Haya (see Norell \& Barta, 2016, fig.9). At this level, 
270 their lateral margin is particularly thickened. There is obviously no row of foramina along the lateral

271 aspect of the nasal, as observed in Jeholosaurus (Xu et al., 2000; Barrett \& Han, 2009). The caudolateral

272 border of the nasal is notched by the contact facet for the prefrontal. Its caudal margin forms a concave

273 articular surface for the frontal (Fig. 3). The dorsal surface of the paired nasals forms a deep longitudinal

274 depression (Fig. 4), present in a number of basal neornithischians (Barrett et al., 2005), basal

275 ornithopods, and ceratopsians, but which appears better developed than in other taxa in which this

276 structure was described so far, including Jeholosaurus (Xu et al., 2000; Barrett \& Han, 2009), Haya

277 (Makovicky et al., 2011), Liaoceratops (Xu et al., 2002a), and Yinlong (Xu et al., 2006).

278

279

Prefrontal - the prefrontal is a strap-like element that participates in the rostrodorsal margin of the orbit. It articulates with the lacrimal ventrally, the nasal medially and overlaps the frontal caudally (Figs. 3 and 4). Its straight lateral border forms an extended articulation surface with the palpebral. There is no ventral process descending from the rostral end of the prefrontal, as observed in Orodromeus (Scheetz, 1999) and Haya (Makovicky et al., 2011).

Supraorbital - The rostral end of the supraorbital forms a medial and a rostral process that both articulate with the lateral edge of the prefrontal. Its caudal process is robust, straight and particularly, long spanning over nearly the entire diameter of the orbit (Fig. 4). However, it likely did not articulate with the postorbital as in Agilisaurus (Peng 1992; Barrett et al. 2005). There is no trace of a postpalpebral in articulation with the postorbital, as observed in Thescelosaurus (Boyd, 2014) and Haya (Makovicky et al., 2011). Together with the nasals and the prefrontals, the supraorbitals overhang the antorbital and orbital regions of the skull and likely protected those sensitive areas in life.

Frontal - In dorsal view, the frontal is subrectangular and slightly convex rostrocaudally. It is particularly rostrocaudally elongated, more than two times as long the parietal, and mediolaterally narrow: its maximum length to width ratio is $>4$ (Fig. 4). It therefore contrasts with the distinctly wider frontal in other basal ornithichians, ornithopods, and ceratopsians: Jeholosaurus (3: Barrett \& Han, 2009), Agilisaurus (3.0: Peng, 1992), Hexinlusaurus (2,2: He \& Cai, 1984), Hypsilophodon (3.2: Galton, 1974), Zephyrosaurus (3.0: Sues, 1980), Orodromeus (2.2: Scheetz, 1999), Thescelosaurus (1.9, Galton, 1997), Liaoceratops (2.2: Xu et al., 2002a), Psittacosaurus (1.8: Sereno et al., 1988), and Yinlong (1.8: Xu et al., 2006). Each frontal forms about three quarters of the dorsal margin of the orbit, and the orbital rim is 
302

303

304

305

306

307

308

309

310

311

312

313

314

315

316

317

318

Jeholosaurus (Barrett \& Han, 2009), and Haya (Makovicky et al., 2011), the frontal comprises approximately $50 \%$ of the dorsal orbital margin. Rostrally, the paired frontals wedge between the nasals and are slightly overlapped by the prefrontals along their orbital margins. Caudolaterally, they form a straight contact with the postorbital and their caudal border is notched by the rostral process of the parietal. The frontals are excluded from the margin of the supratemporal fenestra by a direct contact between the postorbital and parietal (Figs. 3 and 4).

Parietal - The parietal is wide and robust, and its dorsal surface is regularly convex without any trace of a sagittal crest (Figs. 3 and 4), unlike in Jeholosaurus (Barrett \& Han 2009), Haya (Makovicky et al., 2011), Hypsilophodon (Galton, 1974) and Zephyrosaurus (Sues, 1980). Rostrally, the parietals form a rounded process that wedges between the caudal margins of the frontals; in Jeholosaurus, on the contrary, the parietals are notched at the midline to receive a short triangular process from the caudal margin of the frontals (Barrett \& Han, 2009). Lateral to this point, the margin of the parietal produces a sinuous articulation with the frontals in dorsal view. The paired parietals are slightly constricted in dorsal view at the level of the middle part of the supratemporal fenestra. The rostrolateral corner of the parietal flares laterally. The caudolateral corner of the parietal also extends laterally to contact the squamosal. The caudal border of the parietals forms a straight articulation with the supraoccipital. In Jeholosaurus (Barrett \& Han, 2009) and Haya (Makovicky et al., 2011), the caudal edge of the parietal is deeply notched at the midline. There is no trace of a nuchal crest in Changmiania.

Supraoccipital - The surface of the supraoccipital is highly eroded in both the holotype and referred specimen. Moreover, the occipital region of both specimens is still embedded in the sediments. The supraoccipital is inserted between the lateral wings of the caudal end of the parietal and has a rhomboidal outline. It is steeply inclined rostrodorsally.

Postorbital - In lateral view, the postorbital has the shape of an inverted ' $L$ ' and is formed by a jugal and a squamosal processes, meeting at an angle of about 90 degrees (Fig. 2, Fig. 6B). Unlike other basal neoceratopsians, ornithopods and ceratopsians, the postorbital is not rostrocaudally widened at the level of the junction between both processes, so that it does not look subtriangular in lateral view; consequently, the dorsal portion of the infratemporal fenestra is rostrocaudally wider than its ventral portion, so that the infratemporal fenestra is triangular in shape (Figs. 2 and 6B), contrasting with the elliptical infratemporal fenestra, with a dorsoventral long axis and a reduced dorsal margin, in other 
334 basal neoceratopsians, ornithopods and ceratopsians described so far. The postorbital and

335

336

337

338

infratemporal fenestra more closely resemble the condition in Heterodontosaurus (Charig \& Crompton, 1974). The jugal process is straight, slightly inclined rostrocaudally, and, as already described, its rostrocaudal length remains equal along its whole height. It forms the dorsal half of the caudal margin of the orbit and rostral margin of the infratemporal fenestra; ventrally, it overlaps the dorsal process of the jugal. The squamosal process is quite short and tapers caudally (Fig. 6B); it is overlapped by the rostral process of the squamosal. In dorsal view, the postorbital forms a short medial process that contacts the frontal medially, and the parietal caudomedially. As in Changchunsaurus, there is no trace of rugosities on the lateral surface of the postorbital. Nodular ornamentation is present on the postorbital in Jeholosaurus (Barrett \& Han, 2009), and in some basal ceratopsians (e.g., Archaeoceratops: IVPP V11114) and Yinlong (Xu et al., 2006). In Haya (Makovicky et al., 2011), Zephyrosaurus (Sues, 1980) and Orodromeus (Scheetz, 1999), a rugose crest, which could have served as an area of attachment for the postpalpebral, projects from the orbital rim near the juncture of the ventral and medial rami, (Makovicky et al., 2011).

Squamosal - The squamosal participates in the caudal and lateral margins of the supratemporal fenestra, and in the dorsocaudal margin of the infratemporal fenestra. The rostral process is particularly long and perfectly straight (Figs. 2 and 6B), as a consequence of the important rostrocaudal elongation of the dorsal margin of the infratemporal fenestra; it largely overlaps the squamosal process of the postorbital (Fig. 6B). The medial process is robust and triangular in dorsal view; its dorsal surface is inclined caudoventrally. The dorsolateral corner of the squamosal forms a prominent caudal boss, which forms the dorsocaudal corner of the skull in lateral view (Fig. 6B). The quadrate cotyle is cup-shaped; the pre-and postquadratic processes are not preserved.

Quadrate - The quadrate closely resembles that of Changchunsaurus (Jin et al., 2010): its dorsal portion is distinctly curved caudally, so that its articulation with the squamosal is located caudal to the level of the ventral quadrate condyles (Figs. 2 and 6C). The lateral wing of the quadrate is wide and concave rostrocaudally; its rostral border is sigmoidal in lateral view and participates in the caudodorsal margin of the infratemporal fenestra (Fig. 6C); ventrally, it is particularly thickened along its long contact area with the quadratojugal. Ventrally, the lateral condyle is partially exposed on the right quadrate; it is distinctly offset below the level of the maxillary tooth row, as observed in virtually all ornithischians, including basal forms such as Lesothosaurus (Norman et al., 2004b; Jin et al., 2010).

Peer] reviewing PDF | (2020:05:48592:1:1:NEW 31 Jul 2020) 
367 Quadratojugal - The quadratojugal is trapezoidal in lateral view and mediolaterally compressed (Figs.2 and $6 \mathrm{C})$; it participates in the caudoventral margin of the infratemporal fenestra. Its caudal portion extensively overlaps the rostroventral margin of the quadrate, but it does not reach the ventral process of the squamosal, unlike in Heterodontosaurus (Crompton \& Charig, 1962), Lesothosaurus (Sereno, 1991), and the basal iguanodontians Dryosaurus and Dysalotosaurus (Norman, 2004). The rostral portion of the quadratojugal is overlapped by the caudal ramus of the jugal. As in Changchunsaurus (Jin et al., 2010), Parksosaurus (Galton, 1973), and some specimens of Orodromeus (Scheetz, 1999), there is no trace of a quadratojugal foramen; a circular foramen pierces the lateral surface of the quadratojugal in Hypsilophodon (Galton, 1974), Jeholosaurus (Xu et al., 2000), Haya (Makovicky et al., 2011), and Tenontosaurus (Winkler et al., 1997). Caudoventrally, the quadratojugal extends above the quadrate condyles, as also observed in most basal cerapodans, including Hypsilophodon (Galton, 1974), Jeholosaurus (Barrett \& Han, 2009), Changchunsaurus (Jin et al., 2010), Haya (Makovicky et al., 2011), Orodromeus (Scheetz, 1999), Psittacosaurus (Sereno et al., 1988), and Yinlong (Xu et al., 2006). In advanced ornithopods, the dorsoventral extent of the quadratojugal is reduced and the ventral margin does not approach the quadrate condyles (Norman, 2004).

Jugal - As in Jeholosaurus (Barrett \& Han, 2009), Changchunsaurus (Jin et al. 2010), and basal neoceratopsians (You \& Dodson, 2003; Xu et al., 2002a, 2006), the jugal is bowed outwards quite strongly along its length (Fig. 3). As in Haya (Makovicky et al., 2011), the lateral surface of the jugal lacks the ornamentation or jugal bosses seen in Jeholosaurus (Barrett \& Han, 2009), Changchunsaurus (Jin et al., 2010), Orodromeus (Scheetz, 1999), and Zephyrosaurus (Sues, 1980). The rostral process of the jugal regularly tapers rostrally; it forms the ventral margin of the orbit and contacts the maxilla and the lacrimal (Fig. 6C). The dorsal process of the jugal is slightly inclined caudodorsally. It is laterally overlapped by the jugal process of the postorbital and participates in the ventral halves of the rostral margin of the infratemporal fenestra and of the caudal margin of the orbit. The caudal process is rather short, dorsoventrally high and mediolaterally compressed. It forms the ventral margin of the infratemporal fenestra. Its suture with the quadratojugal is rather complex: ventrally, it forms a long and slender projection extending below the ventral edge of the quadratojugal (Fig. 6C). There is no dorsocaudal projection, so that the caudal end of the jugal does not appear bifid as in Jeholosaurus (Barrett \& Han, 2009), Haya (Makovicky et al., 2011), Thescelosaurus (Boyd, 2014), and possibly 
400

401

Predentary - The predentary is partly eroded and only visible in right lateral view (Fig. 2). It is an elongate arrow-shaped element that tapers rostrally to a sharp, slightly upturned, point, as also observed in Jeholosaurus (Xu et al., 2000), Changchunsaurus (Jin et al., 2010), and Archaeoceratops (You \& Dodson, 2003). Along the lateral side of the predentary, a horizontal sulcus separates the rostrolateral and the rostroventral processes. The caudoventral process is particularly elongated and slightly bowed rostroventrally, extending along the rostroventral border of the dentary.

407

Dentary - The dentary is elongated and rather robust, forming about $56 \%$ of the length of the mandible (Fig. 2). Its ventral margin is regularly convex in lateral view, contrasting with the straighter ventral margin in Hypsilophodon (Galton, 1974), Jeholosaurus (Barrett \& Han, 2009), Changchunsaurus (Jin et al., 2010), and Haya (Makovicky et al., 2011; Norell \& Barta, 2016). Its dorsal and ventral margins remain subparallel along most of their length. The rostral end of the dentary is not slightly downturned as in Changchunsaurus (Jin et al., 2010). The lateral side of the dentary is dorsoventrally convex; the tooth row is strongly inset and is separated from lateral side of the dentary by a well-developed buccal platform, limited ventrally by a low ridge. There is no trace of a rugose thickening of the rostrodorsal margin of the dentary and of a horizontal groove extending ventral and adjacent to the tooth row, as observed in Changchunsaurus (Jin et al., 2010). The height of the buccal emargination is constant. The lateral surface of the dentary is irregularly pierced by small foramina. The number of dentary teeth cannot be ascertained in the holotype, because they are obscured by the overlying maxillae. An edentulous diastema was likely developed along the rostral portion of the dentary, as in Changchunsaurus (Jin et al., 2010). Caudally, the dentary contributes to the rostral half of a high and stout coronoid process that slopes caudodorsally. The position of the last dentary teeth relatively to the coronoid process cannot be observed. The caudal border of the dentary is dorsoventrally concave and overlaps the lateral surfaces of the angular and surangular. At mid-height, it forms a large triangular spur that extends caudally between the angular and surangular (Fig. 7). This spur is slightly developed in Hypsilophodon (Galton, 1974), Jeholosaurus (Barrett \& Han, 2009), Haya (Makovicky et al., 2011), but is absent in Changchunsaurus (Jin et al., 2010) and Thescelosaurus (Boyd, 2014). The dentary forms a triangular rostral process, which is limited dorsally and ventrally by articular facets (Fig. 2): the dorsal facet articulates with the caudolateral process of the predentary and faces rostrally and slightly 
430

431

432

433 434

medially, whereas the ventral facet that contacts the caudoventral process of the predentary is much longer and faces ventrolaterally.

The dentary teeth are present in their sockets, but they are obscured by the sediment or the overlying maxillary teeth. Therefore, they cannot adequately be described.

Surangular - The right surangular is partly exposed in lateral view, but a large portion is obscured by the jugal and quadratojugal (Figs. 2 and 7). The surangular forms the caudal half of the coronoid process. Its lateral margin forms a wide concave sulcus, close to the junction with the dentary and angular.

Angular - The angular is a rostrocaudally-elongated element that forms the posteroventral portion of the mandible (Figs. 2 and 7). It contacts the dentary rostrally and is overlapped dorsally by the surangular. Its lateral surface is dorsoventrally convex. It forms a long caudoventral process that supports the articular and the ventral surface and participates in the ventral margin of the retroarticular process (Fig. 7). The rostral portion of the ventral border of the angular is straight, then it becomes distinctly concave, so that the caudoventral margin of the mandible looks notched and the mandibule sigmoidal in lateral view. The ventral margin of the angular is slightly concave in the holotype of Haya (Makovicky et al., 2011; Norell \& Barta, 2016), although it is straight to slightly convex in Hypsilophodon (Galton, 1974), Jeholosaurus (Barrett \& Han, 2009), and Changchunsaurus (Jin et al., 2010).

Articular - The articular is relatively massive and is inserted between the angular ventrally and the surangular laterally. It forms a prominent retroarticular process that extends caudally over $1 \mathrm{~cm}$ beyond the caudal margin of the quadrate (Fig.7).

\section{Axial skeleton}

The complete vertebral series is preserved and mostly articulated in the holotype specimen. Only the very tip of the tail is potentially missing. However, because the specimen lies on its belly, the vertebrae are still partly embedded within the matrix, and in most cases, only the neural arches and spines are visible. The important extension of ossified tendons along the dorsals and sacrals and the presence of articulated ribs further complicates the description of the vertebral series. 
461 Cervical vertebrae and ribs - The neck of Changmiania is extremely shortened, formed by only 6

462 vertebrae, as observed in both the holotype and referred specimen. In basal ornithischians, ornithopods 463 and ceratopsians, the neck is usually composed of nine vertebrae, as occurs in Heterodontosaurus 464 (Santa Luca, 1980), Hexinlusaurus (He and Cai, 1984; Barrett et al., 2005), Agilisaurus (Peng, 1992),

465

466

467

468

469

470

471

472

473

474

475

476

477

478

479

480

481

482

483

484

485

486

487

488

489

490

491

492 Hypsilophodon (Galton, 1974), Jeholosaurus (Han et al., 2012), Changchunsaurus (Butler et al., 2011), Haya (Makovicky et al., 2011), and Orodromeus (Scheetz, 1999). Psittacosaurus species possess 8 or 9 cervical vertebrae (Sereno, 1987), basal neoceratopsians usually 10 (You and Dodson, 2004), and iguanodontians also have more than 9 cervical vertebrae. In ornithischians a reduced number of cervical vertebrae is observed in the thyreophoran lineage, with 8 cervicals in Scelidosaurus (Norman, 2020), and 7 to 8 cervicals in ankylosaurs (Vickaryous et al., 2004).

Cranially, a discrete atlantal intercentrum is tentatively identified on the left side of the specimen, although it is still nearly completely embedded in the matrix. The centrum of the axis appears longer than that of the succeeding cervical vertebrae (Fig. 8A). Its lateral surface is strongly concave craniocaudally. The diapophysis is visible on the right lateral surface of the centrum, close to the suture with the neural arch. It means that the axial rib (not preserved in this specimen), was double-headed, as in Agilisaurus (Peng, 1992), Jeholosaurus (Han et al., 2012), Haya (Makovicky et al., 2011), Orodromeus (Scheetz 1999), and Psittacosaurus, contrasting with the single-headed axial ribs in Hypsilophodon (Galton, 1974) and Changchunsaurus (Butler et al., 2011). In lateral view, the neural spine is oriented posterodorsally at an angle of about 30 degrees to the horizontal. It is particularly elongate, extending well beyond the caudal border of the axial centrum to overlap cervical vertebra 3 , as also observed in Lesothosaurus (Sereno, 1991), Heterodontosaurus (Santa Luca, 1980), Jeholosaurus (Han et al., 2012), Changchunsaurus (Butler et al., 2011), and Haya (Makovicky et al., 2011). Along its midline, the spine forms a particularly sharp crest extending along its entire length. The posterior margin of the axial neural spine is expanded transversely to form a frill-like plate above the cranial aspect of cervical 3 . The postzygapophyses are set on the laterocaudal corner of the frill and face ventrally.

The longest cervical is cervical 3; then, there is apparently a slight decrease in length until cervical 6, as also noticed in Changchunsaurus (Butler et al., 2011). The cervical centra appear less elongated than in Oryctodromeus (Krumenacker, 2017). The lateral surfaces of the centra are concave both anteroposteriorly and dorsoventrally. The neural arch of cervical 3 is much longer than its corresponding centrum, resembling a somewhat reduced version of the axial neural arch (Fig. 8A). Its caudal margin is also slightly expanded transversely, supporting robust ventrally-facing postzygapophyses. The neural arches become progressively shorter through cervicals $3-6$. On the 
493

494

495

496

497

498

499

500

501

502

503

504

505

506

507

508

509

510

511

512

513

514

515

516

517

518

519

520

521

522

523

524

contrary, the diapophyses become progressively more robust and elongate. On cervical 4 , the diapophyses projects caudoventrally, forming an angle of approximately $45^{\circ}$ with the horizontal plane in lateral view (Fig. 8A); on cervicals 5 and 6, their orientation gradually changes from caudoventral to caudolateral. At their base, the prezygapophyses are prominent, facing dorsomedially. The neural spine is incipiently developed on cervical 3, as is usual in small ornithischians; it is distinctly better developed both in Jeholosaurus (Han et al., 2012) and Changchunsaurus (Butler et al., 2011). The neural spines gradually become more prominent and hook-like on cervicals 4-6 (Fig. 8B, 8C). The postzygapophyses remain large and robust, but progressively face more laterally.

Cervical ribs 4-6 are partially preserved and progressively increase in length. Rib 4 is clearly double-headed (Fig. 8B).

Dorsal vertebrae and ribs - All the dorsal vertebrae are concealed by matrix, and their dorsal surface is covered by a dense lattice of ossified tendons (Fig. 8B), so that their description is very limited. There are 15 or 16 dorsal vertebrae in Changmiania, as also reported in Hypsilophodon (Galton, 1974), Jeholosaurus (Han et al., 2012), Changchunsaurus (Butler et al., 2011), and Haya (Makovicky et al., 2011); the dorsal series of heterodontosaurids and basal neoceratopsians appears shorter, with 13 dorsals reported in Heterodontosaurus (Sereno, 2012) and 12 in Archaeoceratops (You \& Dodson, 2003). The transverse processes lie at the same level as the zygapophyses, as is usual in basal ornithopods (Norman et al., 2004a). At the cranial end of the dorsal series, the transverse processes are oriented dorsolaterally, but they rapidly shift to a more horizontal orientation further toward the sacrum. The neural spines are rather low; they are inclined caudally at the cranial end of the dorsal series, but progressively become more vertical further toward the sacrum. At the caudal end of the dorsal series, several neural spines appear fused together.

Dorsal ribs are rather robust; the longest lie along the level of dorsals 5-8 (Fig. 8B). The anterior dorsal ribs are dorsoventrally compressed, strongly curved, and are slightly grooved along their cranial and caudal surfaces. The last dorsal rib is notably short and robust and projects laterally; its distal extremity lies about the level of the cranial end of the preacetabular process of the ilium. It is apparently single-headed.

Sacral vertebrae - Only the neural spines of the sacral vertebrae are visible on the holotype specimen. They are completely fused together, forming a craniocaudally-elongated continuous bar (Fig. 9A), whose apex lies slightly dorsally to the level of the dorsal edge of the ilium. Such a complete fusion is unusual in 
525 small ornithischians, although it might also be explained by ontogeny. The number of sacral vertebrae

526 cannot be adequately estimated in Changmiania. Six sacral vertebrae occur in many basal ornithischians, 527 ornithopods, and ceratopsians, including Heterodontosaurus (Sereno, 2012), Fruitadens (Butler et al.,

528 2012), some specimens of Hypsilophodon (Galton, 1974), Jeholosaurus (Han et al., 2012), Haya

529 (Makovicky et al., 2011), Orodromeus (Scheetz, 1999), Parksosaurus, Thescelosaurus (Norman et al., 530 2004a), Psittacosaurus and Archaeoceratops (You and Dodson, 2003). Five sacral vertebrae are present

531 in some basal ornithischians, including Lesothosaurus (Sereno, 1991), Agilisaurus (Peng, 1992),

532 Hexinlusaurus (He and Cai, 1984; Barrett et al., 2005), probably Eocursor (Butler et al., 2007), and some

533 specimens of Hypsilophodon (Galton, 1974). Sacra with more than six sacral vertebrae occur in

534 Oryctodromeus, likely Orodromeus (Varricchio et al., 2007), derived iguanodontians (Norman, 2004) and 535 ceratopsians (Dodson et al., 2004).

536

537 Caudal vertebrae - Thirty-six caudal vertebrae are preserved in the holotype specimen. Only a few 538 distalmost vertebrae are possibly missing. The tail is particularly long, making up to $55 \%$ of the total 539 length of the animal, and robust (Figs. $1 \mathrm{~A}$ and $1 \mathrm{C}$ ). The neural spines are developed along the 18 540 proximal vertebrae (Fig. 9B). Their height progressively decreases towards the distal end of the tail.

541 More distally, the neural spine forms a low ridge along the dorsal surface of the neural arch. Overall, the 542 neural spines look more elongated proximodistally than in Hypsilophodon (Galton, 1974), and Haya 543 (Makovicky et al., 2011).

544 The transverse processes of the proximal caudals are particularly prominent, tapering distally to 545 a rounded terminus; they project horizontally and curve slightly posteriorly in their distal part (Fig. 9A).

546 Passing through the caudal series, the transverse processes progressively become shorter,

547 proportionally more massive, with a distal end that is slightly expanded proximodistally. The transverse 548 processes completely disappear at about the level of the $20^{\text {th }}$ caudal. The prezygapophyses extend 549 proximally from the base of the neural arch to cover the postzygapophyses of the preceding vertebra, 550 set at the ventrocaudal corner of the neural spine. The articular facets of the pre-and postzygapophyses 551 are nearly vertical. The centrum of the distal caudal vertebrae becomes progressively more elongated 552 proximodistally, becoming up to 4.5 times as long as high (Fig. 9C). Distal caudals remain proportionally 553 shorter in Jeholosaurus (twice as long as high: Han et al., 2012). Both the pre- and postzygapophyses 554 become very elongate, extending well beyond the proximal and distal limits of the centrum and 555 exhibiting considerable overlap. The articular facets of the zygapophyses remain almost vertically 556 inclined. 
558 Ossified tendons - The ossified tendons form a particularly dense lattice alongside the neural spines of

559

560

561

562

563

564

565

566

567

568

569

570

571

572

573

574

575

576

577

578

579

580

581

582

583

584

585

586

587

588 the dorsal and sacral vertebrae, extending cranially up to the dorsal surface of second dorsal vertebra (Figs. 8B and 8C). They are completely absent from the tail region. The tendons are relatively robust, and cylindrical in cross-section. They lack a distinct lattice-like arrangement and appear to be arranged in linear bundles. This distribution of ossified tendons is similar to that in the basal ornithischians Lesothosaurus (Thulborn, 1972), Agilisaurus (Peng, 1992), and Heterodontosaurus (Santa Luca, 1980), some basal ornithopods including Jeholosaurus (Han et al., 2012) and Haya (Makovicky et al., 2011). However, there is no evidence for the tendons extending onto anterior dorsal vertebrae in Jeholosaurus (Han et al., 2012). In Hypsilophodon and Oryctodromeus, ossified tendons are also present alongside the dorsal and sacral regions, but they extend up to the distal part of the tail (Galton, 1974; Krumenacker, 2017). In Psittacosaurus xinjiangensis, ossified tendons extend on the proximal part of the tail (Sereno \& Zhao, 1988). In the heterodontosaurid Tianyulong, few epaxial ossified tendons are present near the neural arches of the posterior dorsal, sacral and anterior caudal vertebrae, but a sheath of ossified tendons starts around the seventh caudal vertebra, spanning the neural spines and chevrons and considerably stiffening the mid and distal portions of the tail (Sereno, 2012).

\section{Appendicular skeleton}

Scapula - Although the scapula and coracoid are completely fused, their respective limits can still be discerned (Fig. 10A-C). Fused scapulocoracoids can also be observed in Oryctodromeus (Varricchio et al., 2007), Koreanosaurus (Huh et al., 2010), and Haya (Makovicky et al., 2011). The scapula is bowed medially to follow the contour of the rib cage. Its proximal plate is dorsoventrally expanded. A wide deltoid fossa is developed on the lateral side of the proximal plate of the scapula, being limited by a massive deltoid ridge (Fig. 10C). As in Zephyrosaurus, Orodromeus (Scheetz, 1999), Oryctodromeus (Varricchio et al., 2007), and Koreanosaurus (Huh et al., 2010), a strong scapular spine projects craniodorsally. As also observed in Koreanosaurus (Huh et al., 2010), the cranioventral angle of the scapula forms a large buttress for attachment site of a strong $m$. triceps scapularis lateralis externus With a ratio 'length / minimal height of the scapula' $=6.2$, the scapular blade is also relatively robust. The distal end of the scapula is better preserved in the referred specimen JLUM LFV022 (Fig. 1C). As is usual in basal ornithopods, the ventral margin of the scapular blade is markedly concave in lateral view; however, the dorsal margin is also concave, although it remains nearly perfectly straight in e.g. 
589 Hypsilophodon (Galton, 1974), Jeholosaurus (Han et al., 2012), Changchunsaurus (Butler et al., 2011), 590 Haya (Makovicky et al., 2011), Zephyrosaurus, Orodromeus (Scheetz 1999, fig.19), Thescelosaurus 591 (Gilmore, 1915), and Kulindadromeus (Godefroit et al., 2014). Consequently, the distal end of the 592 scapula is expanded both ventrally and dorsally in Changmiania, although the ventral expansion remains 593 more important, contrasting with the more asymmetrical ventral expansion in other basal ornithopods. 594 The caudal scapular blade of Oryctodromeus is characterized by a much larger surface area relative to 595 the overall size of the scapulocoracoid when compared with other ornithischians and ornithopods, 596 allowing for larger muscles attachment sites (Feron \& Varricchio, 2016).

597 Coracoid - The coracoid closely resembles that of Hypsilophodon (Galton, 1974), Orodromeus (Scheetz, 598 1999), and Changchunsaurus (Butler et al., 2011). In lateral view, it is subquadrate, with a convex cranial 599 margin, and forms a robust cranioventral hook-like process (Fig. 10A-C). Its ventral margin looks 600 consequently notched. The coracoid forms about half of the glenoid; the glenoid surface of the coracoid 601 is kidney-shaped. The coracoid is transversely expanded caudally at the level of the articular facet for 602 the scapula. The coracoid foramen is small, slit-like, and perforates the bone close to the articular facet 603 for the scapula. The coracoid of Changmiania lacks a prominent cranioventrally extending ridge on its 604 lateral surface, developed in Psittacosaurus (Averianov et al., 2006) and Yandusaurus (He and Cai 1984). 605 Humerus - The right humerus is visible in dorsal view and looks rather slender, contrasting with the 607 much stouter humeri in Oryctodromeus and Koreanosaurus, in which the shafts are relatively shorter and wider relative to the total length of the bone (Fearon \& Varricchio, 2016; Huh et al., 2010). It is distinctly longer than the scapula (Table 1), as in Kulindadromeus (Godefroit et al., 2004), but unlike in Jeholosaurus (PG, pers. obs.), Haya (Makovicky et al., 2011), and likely Oryctodromeus (Fearon \& Varricchio, 2016; Krumenacker, 2017), in which the scapula and humerus are subequal in length. The proximal portion of the humerus is expanded transversely and compressed craniocaudally (Figs. 10A and 10B), with a regularly rounded proximal border. The humeral head forms a distinct thickening on the caudal surface, at the midpoint of the proximal border. The deltopectoral crest is obscured by the right coracoid in the holotype. It appears relatively short in the referred specimen (Fig. 10C), about 1/3 the length of the humerus; it is in any case proportionally shorterand less prominent than in Kulindadromeus (Godefroit et al., 2014). The humeral shaft is slender and slightly compressed craniocaudally, with an elliptical cross-section. The distal end is slightly expanded laterally to form the two articular condyles. The lateral radial condyle and the medial ulnar condyle have similar sizes. The cranial surface of the distal end forms a shallow triangular depressed area (Figs. 10A and 10B). 
622 Ulna and radius - In the holotype, the right ulna is completely preserved and visible in cranial view; the 623 right radius is partly hidden by the ulna (Figs. $10 \mathrm{~A}$ and $10 \mathrm{~B}$ ). The proximal portion of the left ulna is also 624 visible in cranial view. The ulna and radius are distinctly shorter than the humerus (Table 1) and are 625 rather robust. Both are nearly perfectly straight. The olecranon process of the ulna is moderately 626 developed as is usual in basal ornithopods. On the proximal part of the ulna, the craniomedial coronoid process forms a low and rounded crest that progressively merges with the ulnar shaft. The craniolateral coronoid process is better developed and triangular in cranial view; its proximal portion overhangs the proximolateral side of the ulna. Between these processes, the articular facet for the proximal part of the radius is large, triangular and deeply concave. The ulna progressively tapers distally. Its distal end is slightly expanded mediolaterally again. Its cranial side forms a smoothly concave facet, slightly inclined laterally for the distal part of the radius. as the ulna. Its distal end is weakly twisted about its longitudinal axis, as also observed in Haya 635 (Makovicky et al., 2011).

637 Hand - The right carpus and manus are eroded and partly hidden under the skull in the holotype PMOL 638 AD00114 (Figs. 1A and 1B). The following description is therefore based on the referred specimen PMOL 639 LFV022, which has better preserved hands. Only fingers I to III are visible in dorsal view in this specimen 640 (Fig. 10D). They are proportionally short, about half the length of the humerus, as also observed in Hypsilophodon (Galton, 1974), contrasting with the proportionally longer and more slender hand in the heterodontosaurids Heterodontosaurus (Santa Luca 1980), Abrictosaurus, and Tianyulong (Sereno, 2012). Metacarpals I-III are short and robust; as in Hypsilophodon (Galton, 1974), metacarpal III is the smallest, followed by metacarpals II and I. In Heterodontosaurus and Tianyulong, metacarpal II is the longest, followed by metacarpals III and I (Sereno, 2012). The distal ends of metacarpal I-III appear slightly divergent, although they appear more closely packed, running parallel with each other, in Hypsilophodon (Galton, 1974). The phalangeal count is 2-3-?-?-?, as usual in basal ornithischians including Abrictosaurus, Hypsilophodon, and Hexinlusaurus (Norman et al., 2004a). Phalanges II-2 and III-

6492 are particularly short. The ungual of digit I appears rather massive and recurved towards the palmar 650 side of the hand. 
652 Ilium - The ilium of Changmiania closely resembles that of the basal neoceratopsian Auroraceratops 653 (Morschhauser et al., 2019, fig. 21). Its dorsal margin is regularly convex along the whole length of the 654 bone (Fig. 11A). It is straighter above the main plate and postacetabular process e.g. in Kulindadromeus 655 (Godefroit et al., 2014), Haya (Makovicky et al., 2011), Jeholosaurus (Han et al., 2012), and 656 Thescelosaurus (Gilmore, 1915). As also described in Kulindadromeus (Godefroit et al., 2014), the 657 preacetabular process is about $40 \%$ of the ilium length, dorsoventrally narrow and strongly deflected 658 ventrally, reaching the level of the pubic peduncle. The preacetabular process is distinctly shorter and 659 more slender in Oryctodromeus (Krumenacker, 2017). As in Jeholosaurus (Han et al., 2012), Haya 660 (Makovicky et al., 2011), Hexinlusaurus (He and Cai, 1984), and Hypsilophodon (Galton, 1974), the 661 postacetabular process is slightly shorter, but dorsoventrally much higher than the preacetabular 662 process, contrasting with the dorsoventrally narrow postacetabular process in Kulindadromeus 663 (Godefroit et al., 2014). In Orodromeus, the postacetabular process is relatively longer than the 664 preacetabular process (Scheetz, 1999), whereas the postacetabular process of Heterodontosaurus 665 accounts for only $\sim 25 \%$ of total ilium length (Santa Luca, 1980). There is no trace of a supraacetabular 666 crest along its lateral surface. As in Kulindadromeus (Godefroit et al., 2014), Haya (Makovicky, 2011), 667 and Auroraceratops (Morschhauser et al., 2019), the pubic peduncle is prominent, triangular in lateral 668 view, and forms a $45^{\circ}$ angle with the craniocaudal axis of the ilium body; the pubic peduncle is usually 669 much reduced in most Cerapoda (Ösi et al., 2012). The ischiac peduncle projects ventrally and is stouter 670 than the pubic peduncle. The acetabulum is deep and semi-circular, without any trace of a 671 supraacetabular flange and of a medioventral acetabular flange. As in Kulindadromeus (Godefroit et al., 672 2014), Jeholosaurus (Han et al., 2012), Changchunsaurus (Butler et al., 2011), Hypsilophodon (Galton,

673 1974], and Orodromeus (Scheetz, 1999), the posterior portion of the brevis shelf cannot be observed in 674 lateral view; it contrasts with the condition in basal ornithischians such as Agilisaurus (Peng, 1992), 675 Scelidosaurus, Lesothosaurus (Butler, 2005), and Haya (Makovicky et al., 2011), in which the brevis fossa 676 is visible in lateral view. In both the holotype and referred specimen of Changmiania liaoningensis, the 677 paired ilia are not perfectly vertical, as it is the case in most ornithischians, but they are symmetrically 678 inclined dorsomedially, partially covering the sacrum in dorsal view. This inclination is probably not a 679 taphonomic artifact, because the ilia are symmetrically inclined on both the holotype and referred 680 specimens.

681

682 Ischium - Only the distal part of the paired ischial shafts is visible. They are dorsoventrally flattened 683 and slightly expanded transversely, forming a distal ischial symphysis (Figs. 11B and 11C). Unfortunately, 
684 the precise extent of the distal symphysis cannot be accurately estimated in Changmiania. Elongate 685 ischiac symphyses occur Lesothosaurus (Butler, 2005), Eocursor (Butler, 2010), Jeholosaurus (Han et al., 686 2012), and likely in Haya (Makovicky et al., 2011). In Agilisaurus, the symphysis accounts for 687 approximately $50 \%$ of ischial length (Barrett et al., 2005), although the symphysis is much shorter in 688 Hypsilophodon (Galton, 1974).

689 The pubis is covered by sediment and thus not visible in both the holotype and referred specimen of Changmiania liaoningensis.

691

Femur - Both femora are visible in cranial, medial, and lateral view in both the holotype and referred specimen of Changmiania liaoningensis. Their proximal end is hidden under the ilia (Figs. 1A-1C). The femur of Changmiania is rather robust and slightly bowed dorsally (Figs. 11B and 11C). On the proximal portion of the femur, the lesser trochanter is eroded, but appears moderately developed and supported by a low ridge on the laterocranial corner of the proximal part of the femur; its apex lies well below the apex of the greater trochanter and the intertrochanteric cleft seems poorly developed. The cranial aspect of the femoral shaft is very convex. The fourth trochanter is covered by sediments in both the holotype and referred specimen of Changmiania liaoningensis. The distal end of the femur is slightly expanded laterally and compressed craniocaudally. The medial condyle is stouter than the lateral condyle. There is a shallowly concave triangular surface on the cranial side of the distal femur, but there is no real extensor intercondylar groove (Figs. 10B and 10C); this condition is also encountered in the basal ornithopods Hypsilophodon (Galton, 1974: fig.54), Orodromeus (Scheetz, 1999), Jeholosaurus (Han et al., 2012), Changchunsaurus (Butler et al., 2011), and Koreanosaurus (Huh et al., 2010). This groove is much better developed in more derived ornithopods (Butler et al. 2008).

Tibiotarsus - Both tibiae are visible in dorsal view in both the holotype and referred specimen of Changmiania liaoningensis (Figs. 1A-1C); their proximal end is hidden by the overlapping femora. The astragalus and calcaneum are completely fused to the distal end of the tibia so their respective limits can be hardly discerned. The tibia and tarsal element remain free elements in other basal ornithopods, including Hypsilophodon (Galton, 1974), Orodromeus (Scheetz, 1999), Haya (Makovicky et al., 2011), Changchunsaurus (Butler et al., 2011), Jeholosaurus (Han et al., 2012), and Oryctodromeus

713 (Krumenacker, 2017). However, fusion of the tarsal elements to the tibia is regarded as an ontogenetical character in hadrosaurid ornithopods (Godefroit et al., 2012); thus, pending further evidence, we have not included the fusion of the tibiotarsus elements as a diagnostic character for Changmiania. The 
716 tibiotarsus of Changmiania is slender and about $120 \%$ the length of the femur as in most basal

717 ornithopods except Koreanosaurus (see Table 2). The caudal surface of the slender tibial shaft is

718 regularly convex. Its distal end is flattened craniocaudally and slightly widened mediolaterally, with a

719 shallowly concave caudal surface. The distal end of the tibiotarsus is regularly convex craniocaudally and

720 concave mediolaterally. It is more expanded distally at the level of the calcaneum and external malleolus

721 of the tibia than at the level of the astragalus and internal malleolus of the tibia (Figs. 11B and 11C). The

722 medial surface of the astragalus is flattened and inclined caudolaterally. The lateral surface of the

723 calcaneum is depressed; its dorsal border is concave in lateral view, to fit the rounded distal end of the 724 fibula.

725

726 Fibula - The proximal half of the fibula is as robust as the corresponding portion of the tibia (Figs. 11B

727 and 11C), contrasting with the slender, rod-like, and distally-tapering fibula observed in most other basal

728 ornithopods, including Hypsilophodon (Galton, 1974), Orodromeus (Scheetz, 1999), Haya (Makovicky et

729 al., 2011), Changchunsaurus (Butler et al., 2011), Jeholosaurus (Han et al., 2012), and Oryctodromeus

730 (Krumenacker, 2017). Its proximal end is craniocaudally expanded and transversely compressed. It

731 regularly tapers distally, but its distal end is slightly expanded transversely again, with a rounded distal

732 surface, to fit against the dorsal border of the calcaneum. The lateral side of the fibula is regularly

733 convex craniocaudally, whereas its medial surface, which fits against the tibia, is deeply concave.

734

735

Pes - Both pedes are visible in dorsal view (Figs. 11B-D). They are likely complete, but their medial part is covered by the tibiotarsus and fibula. Left digit I is partly exposed on the right foot of the referred

737 specimen. It is particularly short, extending up to the distal border of metatarsal II, and formed by two phalanges. In neither pes is it possible to ascertain the presence or absence of metatarsal 5. The pedal count is thus: 2-3-4-5-?. The metatarsals are tightly appressed to one another (Fig. 11D). Metatarsals II and IV are nearly equal in length and slightly shorter than metatarsal III. Metatarsal III and, especially, metatarsal IV curve laterally in cranial view. The distal articular condyles of the main metatarsals are shallowly developed on metatarsals II and IV, but metatarsal III has distinct lateral and medial condyles. The depression for attachment of the collateral ligaments is shallow on the medial surface of metatarsal II, whereas it is much more pronounced on both the medial and lateral sides of metatarsal III, and on the lateral side of metatarsal IV. pits, and intercondylar processes (Figs. 11B-D). Their enlarged proximal articular surfaces are subdivided 
748 by a median ridge into two concavities. The ungual phalanges of digits 2 to 4 are elongate, exceeding the 749 other phalanges in length, with deep lateral ligament grooves and sharp distal ends. The ungual of digit 7503 is the longest (Fig. 11D), unlike in Changchunsaurus, in which the ungual of digit 2 slightly exceeds the 751 ungual of digit 3 in length (Butler et al., 2011).The ungual of digit 1 is too incompletely preserved in the 752 referred specimen to be adequately described.

753

754 Gastroliths - A clustered mass of a dozen small pebbles is visible between the distal part of the right 755 femur and the proximal part of the tibia in PMOL AD00114 (Fig. 1B). Individual clasts, which range in size 756 from $5 \mathrm{~mm}$ to $13 \mathrm{~mm}$, appear to be quartz or chert and are subangular in shape with a smooth patina 757 (Fig. 11E). They closely resemble the pebble clusters associated with the holotype specimen of Haya 758 griva (Makovicky et al., 2011).

759

760

\section{Phylogenetic analysis}

761

762 Our phylogenetic analysis recovered 48 most parsimonious trees, with a length of 859 steps, a

763 Consistency Index $(\mathrm{Cl})$ of 0.36 and a Retention Index (RI) of 0.62 . The strict consensus of these trees is

764 already well resolved, although the Bremer support remains low for most of the nodes (Fig. 12). This low

765 support is mainly caused by various homoplasies (some of which are functionally significant), which are

766 distributed widely across ornithischian phylogeny. A fully resolved agreement subtree was obtained

767 after the exclusion of 5 unstable 'wilcard' taxa (carried out using the 'Comparisons-Agreement 768 subtree(s)' option of TNT; Fig. 12).

769 Changmiania is placed at the base of the clade Ornithopoda, characterized by the following 770 unambiguous synapomorphies (Tables S2 and S4): rugosities are present on the rostral and dorsal 771 surfaces of the premaxilla; there is a fossa-like depression on the premaxilla-maxilla boundary; the 772 frontals are mediolaterally narrow and rostrocaudally elongate, at least twice as long as wide; in lateral 773 view, the jugal extends ventrally above the distal condyles of the quadrate; and the olecranon process of 774 the ulna is moderately developed.

775 However, Changmiania lacks the following synapomorphies, characteristic for more derived 776 ornithopods : the frontals are dorsally flattened over the orbit (they are still slightly arched in 777 Changmiania); the rostral tip of the dentary is positioned at mid-height in lateral view (positioned above 778 mid-height in Changmiania); the caudal neural spines extend beyond their own centrum (entirely 
779

780

781

782

783

784

785

786

787

788

789

790

791

792

793

794

795

796

797

798

799

800

801

802

803

804

805

806

807

808

809

810

positioned over the centrum in Changmiania); the scapula is longer or subequal to the humerus (the humerus is substantially longer than the scapula in Changmiania); and the ischiac peduncle of the ilium is broadly swollen and projects ventrolaterally (it is much reduced and projects ventrally in Changmiania).

Jeholosaurus shangyuanensis, also from the Lujiatun Beds of western Liaoning, is placed in the clade Jeholosaurinae together with Haya griva and Changchunsaurus parvus (Figs. 12 and 13). Jeholosaurinae is characterized by the following synapomorphies (Tables S2 and S4): a forked caudal ramus of the jugal (dorsocaudal projection absent in Changmiania) and relatively wide coracoid (L/W < 0.6 ; 0.7 in Changmiania).

Jeholosaurinae share with more derived ornithopods the following synapomorphies (Tables S2 and S4): rod-like supraorbitals (in Changmiania, the supraorbitals have a much wider base); the presence of a quadratojugal foramen (absent in Changmiania), 6 fused vertebral centra ( 7 in Changmiania): the longest caudal transverse process is distal to the first caudal vertebra (at the level of the first caudal in Changmiania); and the proximal and distal edges of the cranioventral buttress form an acute, less than $75^{\circ}$ angle ( $>75^{\circ}$ in Changmiania).

The present analysis recovers Kulindadromeus zabaikalicus, from the Middle Jurassic of Siberia (Godefroit et al., 2014), as the sister-taxon of Marginocephalia (Figs. 12 and 13), with whom it shares the following unambiguous synapomorphies: the humeral shaft is strongly bowed laterally along its length in cranial and caudal views (it relatively straighter in Changmiania), and the pubic and iliac peduncles of the ischium are subequal in size, or the iliac peduncle is larger than the pubic peduncle (polarity unknown in Changmiania). Using the same dataset of the main analysis, we tested the alternative placement of Kulindadromeus as the sister-taxon of Cerapoda, as originally hypothesized by Godefroit et al. (2014); this analysis produced shortest trees that are two steps longer than the shortest trees resulted by the unconstrained analysis.

The results of the present phylogenetic analysis are not quite different from most of other recently proposed analyses, including Buchholz (2002), Butler et al. (2008; 2011), Makovicky et al. (2011), Han et al. (2012), Godefroit et al. (2014), and Dieudonné et al. (2016): all those analyses recover Orodrominae, Jeholosaurinae, Parksosaurus, and Thescelosaurus within the clade Ornithopoda. On the contrary, Boyd (2015) places Orodrominae, Jeholosaurinae, Parksosaurus, and Thescelosaurus outside Cerapoda, so that the content of Ornithopoda sensu Boyd (2015) is dramatically reduced, limited to Hypsilophodon and Iguanodondia (except Elasmaria, also recovered outside Cerapoda). It must be noted that the definitions of these clades proposed by Boyd (2015) is nearly identical as those proposed by the 
811 other recent analyses, so the different results can only be interpreted by differences in the character-

812 taxon matrix. As already indicated in the Material and Methods section of this paper, we have used an 813 extensively modified version of the character-taxon matrix published by Dieudonné et al. (2016), which 814 had already incorporated Boyd's (2015) data. Cerapodan relationships will be discussed in more details 815 in a forthcoming paper (Dieudonné et al., 2020).

816

\section{Discussion}

818

Vertebrate fossils unearthed from the lower Lujiatun Beds often retain a three-dimensional form, 820 remaining perfectly articulated without any trace of weathering, scavenging or other disturbance (Meng et al., 2004; Zhao et al., 2007). Moreover, some spectacular specimens from the Lujiatun Beds record exceptional behavioural information, such as evidence of parental care in the basal ceratopsian Psittacosaurus (Meng et al. 2004; Zhao et al., 2007) and avian-like sleeping posture in the troodontid Mei (Xu \& Norell, 2004; Gao et al., 2012). 'Sleeping' Mei specimens display a stereotypical sleeping or resting posture found in living birds: the tail curls forward and under the neck, both the hind and fore limbs lie folded beneath the body, and the neck and head curve back between the shoulder and folded elbow toward the hindlimb (Xu \& Norell, 2004; Gao et al., 2012). Although the three-dimensional position of both the Changmiania liaoningensis holotype and referred specimens is markedly different from the 'sleeping' Mei long specimens and from the stereotypical resting posture in living birds, they share some characteristics also suggesting a resting posture: their body sits on their symmetrically folded hindlimbs, their forelimbs are also symmetrically folded next to their body, with their elbows slightly displaced laterally relative to the trunk (Xu \& Norell, 2004; Gao et al., 2012). Moreover, the trunk and the head of PMOL AD00114 curve laterocaudally, so that its head rests on its right manus. The neck of Mei long was much longer and flexible, so that the head of the 'sleeping' specimens curves back between the shoulder and folded elbow toward the hindlimb (Xu \& Norell, 2004; Gao et al., 2012). The main difference between the Changmiania and Mei 'sleeping' specimens is the orientation of their tail: in Mei, it curls forward and under the neck, whereas it remains nearly perfectly straight, oriented backward in both Changmiania individuals. It must be noted that the tail of Changmiania was likely a rather rigid structure, with limited lateral flexibility: the transverse processes of the proximal caudals are particularly elongated, massive and curved backward, while the pre- and postzygapophyses of the distal 
842 and exhibiting considerable overlap. Curling its tail under its neck in a Mei-like style was therefore likely 843 impossible for Changmiania.

844 Such a perfect preservation of the skeleton in a lifelike posture, as observed in both the 845 holotype and referred specimen of Changmiania liaoningensis and also in countless fossils from the 846 Lujiatun Beds, implies that the animals were rapidly entombed while they were still alive (Meng et al. 847 2004; Zhao et al., 2007). Direct sedimentological investigation of the available Changmiania specimens is unfortunately impossible because they are already too heavily prepared, and we lack information about their discovery context. Zhao et al. (2007) showed that the sediments entombing a herd of juvenile Psittacosaurus skeletons from the Lujiatun Beds near Liu Tai village in western Liaoning represent a lahar (volcanic mudflow), either during the eruptive phase of a nearby volcanic center, or during a noneruptive debris flow that reworked previously deposited volcanic material. This scenario might be extended to other exceptionally preserved specimens from the same beds, but again we lack precise stratigraphic, sedimentological and taphonomic information about those specimens as most were discovered by local farmers and most of them were heavily restored. Gao et al. (2012) argued that lifelike posture of vertebrate fossils from the Lujiatun beds contradicts burial in a low energy lahar at least for those specimens: even a low energy lahar is likely to move a small animal out of a perimortem position.

It has also been proposed that some of the most fossiliferous locations in the Yixian Formation, and particularly in the Lujiatun Beds, are the result of instant catastrophic mass mortality events preserved in tuffaceous ashes (Chang et al., 2008; Gao et al., 2003; Xu \& Norell, 2004); in such a Pompeii-like scenario, the main cause of death for the vertebrates from the Lujiatun beds would have been asphyxiation by toxic volcanic gases of ashes. This hypothesis implies a brief but painful agony, which is certainly not supported by the apparent peaceful posture of the Mei and Changmiania specimens. Faux \& Padian (2007) suggest that death resulting from asphyxiation, toxins and infections can be reflected by an opisthotonic posture (hyperextension of the spine with both neck and tail recurved over the back) of the fossil skeleton; this posture is frequent in the two-dimensionally preserved specimens from the Jianshangou and Dawangzhangzi beds of the Yixian Formation, but is markedly different from the 'sleeping' dinosaurs from the Lujiatun Beds. However, Reisdorf \& Wuttke (2012) interpret the opithotonic posture as a post-mortem rather than a perimortem phenomenom, depending on the varying decay resistance of the soft tissues. Gao et al. (2012) similarly show that the troodontid specimens (and also the Changmiania fossils) from the Lujiatun Beds lack the 'pugulistic'

873 hyperflexion of hands and toes often observed in humans that perished in pyroclastic flows and surges 
874 at Pompeii and Herculanum, interpreted as a perimortem response to death from high temperatures 875 and fire (Mastolorenzo et al., 2010).

876 Meng et al. (2004) and Gao et al. (2012) propose that sudden entrapment in a collapsed

877 underground burrow might be an alternative mechanism explaining the preservation of lifelike postures

878 in small dinosaurs together with the complete absence of weathering and scavenging traces. Varricchio

879 et al. (2007) described fossils of an adult and two juvenile individuals of the basal ornithopod

880 Oryctodromeus, discovered in the expanded distal chamber of a sediment-filled burrow. Based on 881 morphological modifications of its skull and postcranial skeleton, Varricchio et al. (2007) convincingly

882 hypothesized that Oryctodromeus was a burrowing dinosaur. Additional burrows containing

883 Oryctodromeus skeletons were subsequently described in Idaho and Montana, reinforcing previous

884 suggestions of communal and fossorial lifestyle, and even possibly parental care in Oryctodromeus

885 (Krumenacker et al., 2019). Skeletal features observed in Zephyrosaurus, Orodromeus, and

886 Koreanosaurus, together with sedimentological and taphonomic data, suggest that these basal

887 ornithopods might also been specialized for digging (Varricchio et al., 2007; Huh et al., 2010). The

888 phylogenetic analysis presented here (Figs. 12 and 13) places Zephyrosaurus, Orodromeus, and

889 Koreanosaurus in a monophyletic clade named Orodrominae. As already pointed out, Oryctodromeus

890 has not been included in the present phylogenetic analysis. However, previous analyses strongly suggest

891 that Oryctodromeus is also an orodromine (Varricchio et al., 2007; Boyd, 2015; Krumenacker, 2017)).

892 Brown et al. (2013) also place Albertadromeus syntarsus, from the Oldman Fm of Alberta (Canada)

893 amongst Orodrominae. However, this taxon is too fragmentary to be included in the present analysis.

894 Changmiania also displays a series of osteological features that are compatible with a fossorial

895 behaviour in this basal ornithopod. Some extant fossorial vertebrates (e.g. the mole-rat Spalax) dig with

896 their head to some degree, using the top of their broad, firm heads to move, loosen, or compact soil

897 (Hildebrand, 1985). The fused premaxillae and the spatulate shape of the dorsal surface of the snout in

898 Changmiania could represent such an implement. Among ornithopods, fused premaxillae are also

899 present in the orodromine Zephyrosaurus and Oryctodromeus (Sues, 1980; Varricchio et al., 2007;

900 Krumenacker, 2017), and in Changchunsaurus (Jin et al. 2010). However, nuchal crests are particularly

901 developed in head-lifting diggers (Hildebrand, 1985), which is not the case in Changmiania.

902

The postcranial skeleton of Changmiania shares a series of morphological characteristics with

903 actual scratch-digging mammals, including a shortened neck (6 cervical vertebrae), a radius that is

904 significantly shorter (70\%) than the humerus, and short hands (Hildebrand 1985; Elissamburu \& De

905 Santis, 2011). Unfortunately, the ventral side of the ulna is hidden by sediments in both the holotype

Peer) reviewing PDF | (2020:05:48592:1:1:NEW 31 Jul 2020) 
906 and referred specimens of Changmiania: in Koreanosaurus and Orodromeus, the proximal ulna is highly

907 keeled as in Talpidae and in the anteater Tamandua, providing large insertion areas to both extensor 908 and flexor muscles for the carpus and the digits, in relation with the digging function of the hands 909 (Lessertisseur \& Saban, 1967; Hildebrand, 1985; Castiella et al., 1992; Huh et al., 2010). The enlarged,

910 fused scapulocoracoid with prominent acromion and scapular spine, present in Changmiania,

911 Koreanosaurus and Oryctodromeus would have increased attachment areas for muscles that were used 912 to stabilize and operate digging forelimbs (Hildebrand, 1985; Varricchio et al. 2007; Huh et al., 2010; 913 Fearon \& Varricchio, 2016).

914 The hip of Changmiania exhibits some features that might also tentatively be related to a 915 digging behaviour. Actual mammals that dig with the forefeet usually brace with their hindfeet, often 916 supplemented by the tail serving as a prop (Hildebrand, 1985). Burrowing mammals such as the 917 marsupial mole Notoryctes and, especially, Talpidae are able to keep their thighs relatively outspread 918 from the axis of their body for a firmer bracing of the back of their body while digging; the pelvis of

919 Talpidae is roughly horizontally oriented, nearly parallel with the vertebral column, and their 920 acetabulum is consequently positioned higher, preventing torsion while bracing (Lessertisseur and 921 Saban, 1967). In a similar way, the dorsomedial inclination of its paired ilia above its sacrum potentially 922 helped Changmiania to keep its hindlimbs outspread and prevented torsion when digging.

923 The neural spines of the sacral vertebrae are completely fused together in Changmiania, forming a 924 craniocaudally-elongated continuous bar. Reinforcement of the sacropelvic complex, as observed in 925 Changmiania, is also a distinctive feature of scratch-digging mammals and appears to relate to the 926 forces, well in excess of body weight, that converge on the pelvic girdle during bracing with the hind feet 927 (Hildebrand, 1985). The pelvis of Zephyrosaurus, Oryctodromeus and Orodromeus is further reinforced 928 by a direct pubosacral contact, but this region is hidden by sediment in both available Changmiania 929 specimens. As is frequently observed in burrowers (Hildebrand, 1985; Varricchio et al., 2007), the basal 930 portion of the tail is particularly robust in Changmiania, with elongated transverse processes and a high 931 neural spine on the proximal caudal vertebrae.

932 The hindlimb of Changmiania is about twice as long as its forelimb and its tibia is significantly 933 longer than its femur, as in most other small basal ornithopods except Koreanosaurus (Table 2); those 934 hindlimb proportions suggest that Changmiania basically remained an efficient cursorial dinosaur. 935 Moreover, the forelimb and skull modifications remain rather modest, so that Changmiania was 936 obviously not a true subterranean animal, but more likely a facultative digger, as also suggested for 
937 938

Oryctodromeus (Varricchio et al., 2007; Krumenacker, 2017; Fearon \& Varricchio, 2016; Krumenacker et al., 2019).

A possible fossorial behavior in Changmiania therefore supports the hypothesis that both PMOL AD00114 and PMOL LFV022 were suddenly entrapped in a collapsed underground burrow, which would explain their perfect lifelike postures and the complete absence of weathering and scavenging traces, as proposed by Meng et al. (2004) and Gao et al. (2012). Of course, this hypothesis remains fully compatible with the observation that the sediments from the Lujiatun Beds mostly represent a lahar (Zhao et al., 2007). It can be hypothesized that the burrows containing the Changmiania skeletons collapsed during the debris flow episode; we can alternatively imagine that the Changmiania specimens dug their burrow in unstable reworked volcanic material just after the debris flow. Those explanations of course remain pure speculations, as firsthand stratigraphic and taphonomic data are lacking for the currently known Changmiania specimens.

\section{Conclusions}

Changmiania liaoningensis nov. gen., nov. sp., from the Lower Cretaceous Lujiatun Beds of western Liaoning Province (China), is placed at the base of the clade Ornithopoda. The perfect preservation of the skeleton of both its holotype and referred specimen in a lifelike posture implies that the animals were rapidly entombed while they were still alive. Although its hindlimb proportions indicate that Changmiania was an efficient cursorial dinosaur, some of is diagnostic features are tentatively interpreted as adaptations to a fossorial behavior. It is therefore tentatively hypothesized that both Changmiania specimens were suddenly entrapped in a collapsed underground burrow while they were resting.

\section{Acknowledgements}


962 Thanks first and foremost to Sun Ge, Hu Dongyu, and the staff of the Paleontological museum of

963 Liaoning for extensive access to the specimens over the years. D. Barta, E. Brown, R. J. Butler and L.J.

964 Krumenacker provided thoughtful comments on a previous draft of this manuscript that greatly

965 improved its quality.

966

967

References

968

969

970

971

972

973

974

975

976

977

978

979

980

981

982

983

984

985

986

987

988

989

990

991

992

993

994

995

996

997

998

Averianov AO, Voronkevich AV, Leshchinskiy SV, Fayngertz AV. 2006. A ceratopsian dinosaur Psittacosaurus sibiricus from the Early Cretaceous of West Siberia, Russia and its phylogenetic relationships. Journal of Systematic Paleontology 4(4):359-395.

Barrett PM, Butler RJ, Knoll F. 2005. Small-bodied ornithischian dinosaurs from the Middle Jurassic of Sichuan, China. Journal of Vertebrate Paleontology 25:823-834 DOI 10.1671/02724634(2005)025[0823:SODFTM]2.0.CO;2.

Barrett PM, Han F-L. 2009. Cranial anatomy of Jeholosaurus shangyuanensis (Dinosauria: Ornithischia) from the Early Cretaceous of China. Zootaxa 2072:31-55.

Boyd CA. 2014. The cranial anatomy of the neornithischian dinosaur Thescelosaurus neglectus. PeerJ 2:3669 DOI 10.7717/peerj.669.

Boyd CA. 2015. The systematic relationships and biogeographic history of ornithischian dinosaurs. PeerJ 3:e1523 DOI 10.7717/peerj.1523.

Brown CM, Evans DC, Ryan MJ, Russell AP. 2013. New data on the diversity and abundance of small-bodied ornithopods (Dinosauria, Ornithischia) from the Belly River Group (Campanian) of Alberta. Journal of Vertebrate Paleontology 33:495-520 DOI 10.1080/02724634.2013.746229.

Buchholz PW. 2002. Phylogeny and biogeography of basal Ornithischia. In: Brown D E, ed. The Mesozoic in Wyoming. Casper: Tate Geological Museum, 18-34.

Butler RJ. 2005. The 'fabrosaurid' ornithischian dinosaurs of the Upper Elliot Formation (Lower Jurassic) of South Africa and Lesotho. Zoological Journal of the Linnean Society 145:175-218 DOI 10.1111/j.1096-3642.2005.00182.x.

Butler RJ. 2010. The anatomy of the basal ornithischian dinosaur Eocursor parvus from the lower Elliot Formation (Late Triassic) of South Africa. Zoological Journal of the Linnean Society 160:648-684 DOI 10.1111/j.1096-3642.2009.00631.x.

Butler RJ, Jin LY, Chen J, Godefroit P. 2011. The postcranial osteology and phylogenetic position of the small ornithischian dinosaur Changchunsaurus parvus from the Quantou Formation (Cretaceous: Aptian-Cenomanian) of Jilin Province, northeastern China. Palaeontology 54:667-683 DOI 10.1111/j.1475-4983.2011.01046.x.

Butler RJ, Smith RMH, Norman DB. 2007. A primitive ornithischian dinosaur from the Late Triassic of South Africa, and the early evolution and diversification of Ornithischia. Proceedings of the Royal Society B 274:2041-2046 DOI 10.1098/rspb.2007.0367. 
999

1000

1001

1002

1003

1004

1005

1006

1007

1008

1009

1010

1011

1012

1013

1014

1015

1016

1017

1018

1019

1020

1021

1022

1023

1024

1025

1026

1027

1028

1029

1030

1031

1032

1033

1034

1035

1036

Butler RJ, Upchurch P, Norman DB. 2008. The phylogeny of the ornithischian dinosaurs. Journal of Systematic Paleontology 6:1-40 DOI 10.1017/S1477201907002271.

Castiella MJ, Laville E, Renous S, Gasc J-P. 1992. Caractéristiques morphologiques du membre antérieur de la taupe commune, Talpa europaea (Mammalia, Talpidae). Mammalia 56(2):265-285.

Chang MM, Chen PJ, Wang YQ, Miao DS, editors. 2008. The Jehol fossils: the emergence of feathered dinosaurs, beaked birds and flowering plants. New York: Academic Press, 208 pp.

Charig AJ, Crompton AW.1974. The alleged synonymy of Lycorhinus and Heterodontosaurus. Annals of the South African Museum 64:167-189.

Cooper MR. 1985. A revision of the ornithischian dinosaur Kangnasaurus coetzeei Haughton with a classification of the Ornithischia. Annals of the South African Museum 95:281-317.

Crompton AW, Charig AJ. 1962. A new ornithischian from the Upper Triassic of South Africa. Nature 196:1074-1077 DOI 10.1038/1961074a0.

Dieudonné P-E, Cruzado-Caballero P, Godefroit P, Tortosa T. 2020. A new phylogeny of Cerapodan dinosaurs. Historical Biology DOI 10.1080/08912963.2020.1793979.

Dieudonné P-E, Tortosa T, Torcida Fernández-Baldor F, Canudo JI, Díaz-Martínez I. 2016. An unexpected early rhabdodontid from Europe (Lower Cretaceous of Salas de los Infantes, Burgos Province, Spain) and a re-examination of basal iguanodontian relationships. PLoS ONE 11(6):e0156251 DOI 10.1371/journal.pone.0156251.

Dodson P, Forster CA, Sampson SD. 2004. Ceratopsidae. In: Weishampel DB, Dodson P, Osmólska H, eds. The Dinosauria. Second edition. Berkeley: University of California Press, 494-513.

Dollo L. 1888. Iguanodontidae et Camptonotidae. Comptes Rendus de l'Académie des Sciences (Paris) 106:775-777.

Elissamburu A, De Santis L. 2011. Forelimb proportions and fossorial adaptations in the scratchdigging rodent Ctenomys (Caviomorpha). Journal of Mammalogy 92(3):683-689 DOI 10.1644/09MAMM-A-113.1.

Faux CM, Padian K. 2007. The opisthotonic posture of vertebrate skeletons: postmortem contraction or death throes? Paleobiology 33:201-226.

Fearon LF, Varricchio DJ. 2016. Reconstruction of the forelimb musculature of the Cretaceous ornithopod dinosaur Oryctodromeus cubicularis: implications for digging. Journal of Vertebrate Paleontology 36(2):e1078341 DOI 10.1080/02724634.2016.1078341.

Gao C, Morschhauser EM, Varricchio DJ, Liu J, Zhao B. 2012. A second soundly sleeping dragon: new anatomical details of the Chinese troodontid Mei long with implications for phylogeny and taphonomy. PLoS ONE 7(9):e45203 DOI 10.1371/journal.pone.0045203.

Galton PM. 1973. Redescription of the skull and mandible of Parksosaurus from the Late Cretaceous with comments on the family Hypsilophodontidae (Ornithischia). Life Science Contributions, Royal Ontario Museum 89:1-21.

Galton PM. 1974a. The ornithischian dinosaur Hypsilophodon from the Wealden of the Isle of Wight. Bulletin of the British Museum (Natural History) Geology 25:1-152. 
1037

1038

1039

1040

1041

1042

1043

1044

1045

1046

1047

1048

1049

1050

1051

1052

1053

1054

1055

1056

1057

1058

1059

1060

1061

1062

1063

1064

1065

1066

1067

1068

1069

1070

1071

1072

1073

1074

Galton PM. 1997. Cranial anatomy of the basal hypsilophodontid dinosaur Thescelosaurus neglectus Gilmore (Ornithischia: Ornithopoda) from the Upper Cretaceous of North America. Revue de Paléobiologie 16:231-258.

Gilmore CW. 1915. Osteology of Thescelosaurus, an orthopodous dinosaur from the Lance Formation of Wyoming. Proceedings of the United States National Museum 49:591-616 DOI 10.5479/si.00963801.49-2127.591.

Godefroit P, Bolotsky YL, Bolotsky IY. 2012. Osteology and relationships of Olorotitan arharensis, a hollow-crested hadrosaurid dinosaur from the latest Cretaceous of Far Eastern Russia. Acta Palaeontologica Polonica 57(3):527-560 DOI 10.4202/app.2011.0051.

Godefroit P, Sinitsa SM, Dhouailly D, Bolosky YL, Sizov AV, McNamara ME, Benton MJ, Spagna P. 2014. A Jurassic ornithischian dinosaur from Siberia with both feathers and scales. Science 345:451-455 DOI 10.1126/science.1253351.

Goloboff PA, Farris JS, Nixon KC. 2008. TNT, a free program for phylogenetic analysis. Cladistics 24:774-786 DOI 10.1111/j.1096-0031.2008.00217.x.

Han F-L, Barrett PM, Butler RJ, Xing X. 2012. Postcranial anatomy of Jeholosaurus shangyuanensis (Dinosauria, Ornithischia) from the Lower Cretaceous Yixian Formation of China. Journal of Vertebrate Paleontology 32:1370-1395 DOI 10.1080/02724634.2012.694385.

He HY, Wang XL, Zhou ZH, Jin F, Wang F, Yang LK, Ding X, Boven A, Zhu RX. 2006. ${ }^{40} \mathrm{Ar} /{ }^{39} \mathrm{Ar}$ dating of Lujiatun Bed (Jehol Group) in Liaoning, northeastern China. Geophysical Research Letters 33:L04303 DOI 10.1029/2005GL025274.

He XL, Cai KJ. 1984. The Middle Jurassic dinosaurian fauna from Dashanpu, Zigong, Sichuan. Vol. 1. Chengdu, Sichuan Scientific and Technological Publishing House 1-71.

Hildebrand M. 1985. Digging in quadrupeds. In: Hildebrand M, Bramble, DM, Liem KF, Wake DB, eds. Functional vertebrate morphology. Cambridge, MA: Belknap Press, 89-109.

Hu Y, Meng J, Wang Y, Li C. 2005. Large Mesozoic mammals fed on young dinosaurs. Nature 433:149-152. DOI 10.1038/nature03102.

Huh M, Lee D-G, Kim J-K, Lim J-D, Godefroit P. 2011. A new basal ornithopod dinosaur from the Upper Cretaceous of South Korea. Neues Jahrbuch für Geologie und Paläontologie Abhandlungen 259:1-24 DOI 10.1127/0077-7749/2010/0102.

Ji Q, Norrell M, Makovicky PJ, Gao K, Ji S, Yuan C. 2003. An early ostrich dinosaur and implications for ornithomimosaur phylogeny. American Museum Novitates 3420:1-19 DOI: 10.1206/00030082(2003)420<0001:AEODAI >2.0.CO;2

Jin LY, Chen J, Godefroit P. 2012. A new basal ornithomimosaur (Dinosauria: Theropoda) from the Early Cretaceous Yixian Formation, Northeast China. In Godefroit P, ed. Bernissart Dinosaurs and Early Cretaceous Terrestrial Ecosystems. Bloomington and Indianapolis: Indiana University Press, 467-487

Jin LY, Chen J, Zan SQ, Butler RJ, Godefroit P. 2010. Cranial anatomy of the small ornithischian dinosaur Changchunsaurus parvus from the Quantou Formation (Cretaceous: Aptian-Cenomanian) 
1075

1076

1077

1078

1079

1080

1081

1082

1083

1084

1085

1086

1087

1088

1089

1090

1091

1092

1093

1094

1095

1096

1097

1098

1099

1100

1101

1102

1103

1104

1105

1106

1107

1108

1109

1110

1111

1112

1113

of Jilin Province, northeastern China. Journal of Vertebrate Paleontology 30:196-214 DOI 10.1080/02724630903409279.

Krumenacker LJ. 2010. Chronostratigraphy and paleontology of the mid-Cretaceous Wayan Formation of eastern Idaho, with a description of the first Oryctodromeus specimens from Idaho. Provo: Department of Geological Sciences, Brigham Young University, 88 pp.

Krumenacker LJ. 2017. Osteology, phylogeny, taphonomy, and ontogenetic histology of Oryctodromeus cubicularis, from the Middle Cretaceous (Albian-Cenomanian) of Montana and Idaho. Bozeman, Montana: Montana State University, 283 pp.

Krumenacker LJ, Varricchio, DJ, Wilson JP, Martin A, Ferguson A. 2019. Taphonomy of and new burrows from Oryctodromeus cubicularis, a burrowing neornithischian dinosaur, from the midCretaceous (AlbianCenomanian) of Idaho and Montana, U.S.A. Palaeogeography, Palaeoclimatology, Palaeoecology 530:300-311. DOI 10.1016/j.palaeo.2019.05.047.

Lessertisseur J, Saban R. 1967. Squelette appendiculaire. In: Grassé P-P, éd. Traité de Zoologie, tome 16 (1): Mammifères - tégument - squelette. Paris: Masson, 707-1078.

Makovicky PJ, Kilbourne BM, Sadleir RW, Norell MA. 2011. A new basal ornithopod (Dinosauria, Ornithischia) from the Late Cretaceous of Mongolia. Journal of Vertebrate Paleontology 31:626640 DOI 10.1080/02724634.2011.557114.

Marsh OC. 1881. Principal characters of American Jurassic dinosaurs. Part V. American Journal of Science, Series 3 21:417-423.

Mastolorenzo G, Petrone P, Pappalardo L, Guarino FM. 2010. Lethal thermal impact at periphery of pyroclastic surges: evidences at Pompeii. PLoS ONE 5(6): e11127 DOI 10.1371/journal.pone.0011127.

Meng Q, Liu J, Varricchio DJ, Huang T, Gao C. 2004. Parental care in an ornithischian dinosaur. Nature 431: 145-146 DOI 10.1038/431145a.

Morschhauser EM, You H, Li D, Dodson P. 2019. Postcranial morphology of the basal neoceratopsian (Ornithischia: Ceratopsia) Auroraceratops rugosus from the Early Cretaceous (Aptian-Albian) of northwestern Gansu Province, China". Journal of Vertebrate Paleontology. 38 (sup 1.): 75-116. DOI 10.1080/02724634.2018.1524383.

Nopcsa F. 1915. Die Dinosaurier der siebenbürgischen Landesteile. Mitteilungen aus dem Jahrbuche der Koniglich-Ungarischen Geologischen Reichsanstalt 23:1-26.

Norell MA, Barta DE. 2016. A new specimen of the ornithischian dinosaur Haya griva, cross-Gobi geologic correlation, and the age of the Zos Canyon beds. American Museum Novitates 3851:1-19.

Norman DB. 2004. Basal Iguanodontia. In: Weishampel DB, Dodson $\mathrm{P}$, Osmólska H, eds. The Dinosauria. Second edition. Berkeley: University of California Press, 413-437.

Norman DB. 2015. On the history, osteology, and systematic position of the Wealden (Hastings group) dinosaur Hypselospinus fittoni (Iguanodontia: Styracosterna). Zoological Journal of the Linnean Society 173:92-189 DOI 10.1111/zoj.12193.

Norman DB. 2020. Scelidosaurus harrisonii from the Early Jurassic of Dorset, England: postcranial skeleton. Zoological Journal of the Linnean Society 189 (1):47-157. DOI 10.1093/zoolinnean/zlz078. 
1114

1115

1116

1117

1118

1119

1120

1121

1122

1123

1124

1125

1126

1127

1128

1129

1130

1131

1132

1133

1134

1135

1136

1137

1138

1139

1140

1141

1142

1143

1144

1145

1146

1147

1148

1149

Norman DB, Sues H-D, Witmer LM, Coria RA. 2004a. Basal Ornithopoda. In: Weishampel DB, Dodson P, Osmólska H, eds. The Dinosauria. Second edition. Berkeley: University of California Press, 393-412.

Norman DB, Witmer LM, Weishampel DB. 2004b. Basal Ornithischia. In: Weishampel DB, Dodson P, Osmólska H, eds. The Dinosauria. Second edition. Berkeley: University of California Press, 325334.

Ősi A, Prondvai E, Butler R, Weishampel DB. 2012. Phylogeny, histology and inferred body size evolution in a new rhabdodontid dinosaur from the Late Cretaceous of Hungary. PLoS ONE 7(9):e44318 DOI 10.1371/journal.pone.0044318.

Owen R. 1842. Report on British fossil reptiles, part II. Report of the British Association for the Advancement of Science for 1841 9:60-204.

Peng G. 1992. Jurassic ornithopod Agilisaurus louderbacki (Ornithopoda: Fabrosauridae) from Zigong, Sichuan, China. Vertebrata PalAsiatica 30:39-51.

Reisdorf AG, Wuttke M. 2012. Re-evaluating Moodie's oposthotonic-posture hypothesis in fossil vertebrates Part I: Reptiles - the taphonomy of the bipedal dinosaurs Compsognathus longipes and Juravenator starki from the Solnhofen Archipelago (Jurassic, Germany). Palaeobiodiversity and Palaeoenvironments 92(1):119-168 DOI 10.1007/s12549-011-0068-y.

Romer AS. 1966. Vertebrate paleontology. 3rd edition. Chicago: University of Chicago Press, 468 pp.

Santa Luca AP. 1980. The postcranial skeleton of Heterodontosaurus tucki (Reptilia,Ornithischia) from the Stormberg of South Africa. Annals of the South African Museum 79:159-211.

Scheetz RD. 1999. Osteology of Orodromeus makelai and the phylogeny of basal ornithopod dinosaurs. Bozeman: Montana State University, 186 pp.

Seeley HG. 1887. On the classification of the fossil animals commonly named Dinosauria. Proceedings of the Royal Society of London 43:165-171 DOI 10.1098/rspl.1887.0117.

Sereno PC. 1986. Phylogeny of the bird-hipped dinosaurs. National Geographic Research 2:234-256.

Sereno PC. 1991. Lesothosaurus, "fabrosaurids", and the early evolution of Ornithischia. Journal of Vertebrate Paleontology 11:168-197 DOI 10.1080/02724634.1991.10011386.

Sereno PC. 2005. The logical basis of phylogenetic taxonomy. Systematic Biology 54:595-619 DOI 10.1080/106351591007453.

Sereno PC. 2012. Taxonomy, morphology, masticatory function and phylogeny of heterodontosaurid dinosaurs. Zookeys 226:1-225 DOI 10.3897/zookeys.226.2840.

Sereno P, Zhao X. 1988. Psittacosaurus xinjiangensis (Ornithischia: Ceratopsia), a new psittacosaur from the Lower Cretaceous of northwestern China. Journal of Vertebrate Paleontology 8:353-365.

Sereno, PC, Zhao X, Chang Z, Rao C. 1988. Psittacosaurus meileyingensis (Ornithischia: Ceratopsia), a new psittacosaur from the Lower Cretaceous of northeastern China. Journal of Vertebrate Paleontology 8:366-377. 
1150

1151

1152

1153

1154

1155

1156

1157

1158

1159

1160

1161

1162

1163

1164

1165

1166

1167

1168

1169

1170

1171

1172

1173

1174

1175

1176

1177

1178

1179

1180

1181

1182

1183

1184

1185

1186

1187

1188

Shen C, Lü J, Kundrát M, Brusatte SL, Gao H. 2017a. A new troodontid dinosaur from the Lower Cretaceous Yixian Formation of Liaoning Province, China. Acta Geologica Sinica 91(3):763-780 DOI 10.1111/1755-6724.13307.

Shen C, Zhao B, Gao CL, Lü JC, Kundrát M. 2017b. A new troodontid dinosaur (Liaoningvenator curriei gen. et sp. nov.) from the Early Cretaceous Yixian Formation in western Liaoning province. Acta Geoscientica Sinica 38(3):359-371.

Sternberg CM. 1937. A classification of Thescelosaurus, with a description of a new species. Proceedings of the Geological Society of America 1936:375.

Sues H-D. 1980. Anatomy and relationships of a new hypsilophodontid dinosaur from the Lower Cretaceous of North America. Palaeontographica Abteilung a Palaeozoologie-Stratigraphie 169:5172.

Thulborn RA. 1972. The postcranial skeleton of the Triassic ornithischian dinosaur Fabrosaurus australis. Palaeontology 15:29-60.

Varricchio DJ, Martin AJ, Katsura Y. 2007. First trace and body evidence of a burrowing, denning dinosaur. Proceedings of the Royal Society B: Biological Sciences 274:1361-1368 DOI 10.1098/rspb.2006.0443.

Vickarious MK, Maryańska T, Weishampel DB. 2004. Ankylosauria. In: Weishampel DB, Dodson P, Osmólska H, eds. The Dinosauria. Second edition. Berkeley: University of California Press, 363392.

Winkler DA, Murry PA, Jacobs LL. 1997. A new species of Tenontosaurus (Dinosauria: Ornithopoda) from the Early Cretaceous of Texas. Journal of Vertebrate Paleontology 17:330-348 DOI 10.1080/02724634.1997.10010978.

Xu X, Forster CA, Clark JM, Mo J. 2006. A basal ceratopsian with transitional features from the Late Jurassic of northwestern China. Proceedings of the Royal Society B 273:2135-2140 DOI 10.1098/rspb.2006.3566.

Xu X, Makovicky PJ, Wang XL, Norell MA, You HL. 2002a. A ceratopsian dinosaur from China and the early evolution of Ceratopsia. Nature 416:314-317

DOI 10.1038/416314a.

Xu X, Norell MA, Wang XL, Makovicky PJ, Wu X-C. 2002b. A basal troodontid from the Early Cretaceous of China. Nature 415(6873):780-784 DOI 10.1038/415780a.

Xu X, Norell MA. 2004. A new troodontid dinosaur from China with avian-like sleeping posture. Nature 431(7010):838-841 DOI 10.1038/nature02898.

Xu X, Wang X. 2004b. A new dromaeosaur (Dinosauria: Theropoda) from the Early Cretaceous Yixian Formation of Western Liaonong. Vertebrata PalAsiatica 42(2):111-119.

Xu X, Wang X. 2004b. A new troodontid (Theropoda: Troodontidae) from the Lower Cretaceous Yixian Formation of Western Liaoning, China. Acta Geologica Sinica-EngOlish Edition 78(1):22-26 DOI 10.1111/j.1755-6724.2004.tb00671.x.

Xu X, Wang XL, You HL. 2000. A primitive ornithopod from the Early Cretaceous Yixian Formation of Liaoning. Vertebrata PalAsiatica 38:318-325. 
1189

1190

1191

1192

1193

1194

1195

You HL, Dodson P. 2003. Redescription of neoceratopsian dinosaur Archaeoceratops and earl evolution of Neoceratopsia. Acta Palaeontologica Polonica 48:261-272.

Zhao Q, Barrett PM, Eberth DA. 2007. Social behavior and mass mortality in the basal ceratopsian dinosaur Psittacosaurus (Early Cretaceous, People's Republic of China). Palaeontology 50:10231029 DOI 10.1111/j.1475-4983.2007.00709.x. 


\section{Figure Captions}

1197 Figure 1 Changmiania liaoningensis, an ornithopod dinosaur from the Lower Cretaceous of Lujiatun

1198 (Liaoning Province, China). (A) holotype PMOL AD00114 in dorsal view; (B) anterior part of the holotype 1199 PMOL AD00114 in caudolateral view; (C) referred specimen PMOL LFV022 in dorsal view. Red arrows

1200 indicate the emplacement of the gastrolith clusters.

1201 Figure 2 Skull of PMOL AD00114 in right lateral view. (A) photograph; (B) line drawing.

1202 Figure 3 Skull of PMOL AD00114 in left dorsolateral view. (A) photograph; (B) line drawing.

1203 Figure 4 Skull of PMOL AD00114 in dorsal view. (A) photograph; (B) line drawing.

1204 Figure 5 Skull of PMOL AD00114 in right lateral view. (A) close-up of the premaxillary region; (B) close1205 up of the maxillary region; (C) close-up of maxillary teeth.

1206 Figure 6 Skull of PMOL AD00114. (A) antorbital fenestra region in right lateral view; (B) left squamosal 1207 and postorbital in dorsolateral view; (C) caudal half of the skull in right lateral view.

1208 Figure 7 Postdentary bones of PMOL AD00114 in right lateral view.

1209 Figure 8 Axial skeleton of Changmiania liaoningensis. (A) cervical vertebrae 2 to 4 of PMOL AD00114 in 1210 right lateral view; (B) cervical and dorsal series of PMOL AD00114 in left lateral view; (C) neck region of 1211 PMOL LFV022 in right dorsolateral view. Abbreviations: cv: cervical vertebra; d: dorsal vertebra.

1212 Figure 9 Axial skeleton of PMOL AD00114. (A) sacrum and proximal caudal vertebrae in dorsal view; (B) proximal caudal vertebrae in right lateral view; (C) distal caudal vertebrae in left lateral view. Abbreviation: ca: caudal vertebra.

Figure 10 Scapular girdle and forelimb of Changmiania liaoningensis. (A) photograph and (B) line drawing of the right scapular girdle and forelimb of PMOL AD00114; (C) detail of the right scapulocoracoid of PMOL AD00114 in lateral view; D: left forelimb of PMOL LFV022 in dorsal view.

1218 Abbreviation: mc: metacarpal.

Figure 11 Pelvic girdle and hindlimbs of PMOL AD00114. (A) right ilium in lateral view; (B) photograph of distal ischia and right hindlimb; (C) line drawing of distal ischia and right hindlimb; (D) left foot in dorsal view; (E) gastroliths.

1222 Figure 12 Phylogenetic position of Changmiania liaoningensis gen. et sp. nov. among Ornithischia. 1223 Strict consensus tree of 49 MPT's. Tree Length $=859$. Nodal support (Bremer indices $>1$ ) is indicated 1224 above or below the branches.

1225 Figure 13 Phylogenetic position of Changmiania liaoningensis gen. et sp. nov. among Ornithischia.

1226 Fully-resolved agreement subtree obtained after the exclusion of 5 unstable 'wilcard' taxa, carried out using the 'Comparisons-Agreement subtree(s)' option of TNT (Goloboff et al., 2008).

Table 1. Selected measurements of Changmiania liaoningensis PMOL AD00114 specimen. 
1231 foxii, Jeholosaurus shangyuanensis, Nanosaurus agilis, Orodromeus makelai, and Oryctodromeus 1232 cubicularis. 


\section{Figure 1}

Changmiania liaoningensis, an ornithopod dinosaur from the Lower Cretaceous of Lujiatun (Liaoning Province, China).

(A) holotype PMOL AD00114 in dorsal view; (B) anterior part of the holotype PMOL AD00114 in caudolateral view; (C) referred specimen PMOL LFV022 in dorsal view. Red arrows indicate the emplacement of the gastrolith clusters. 

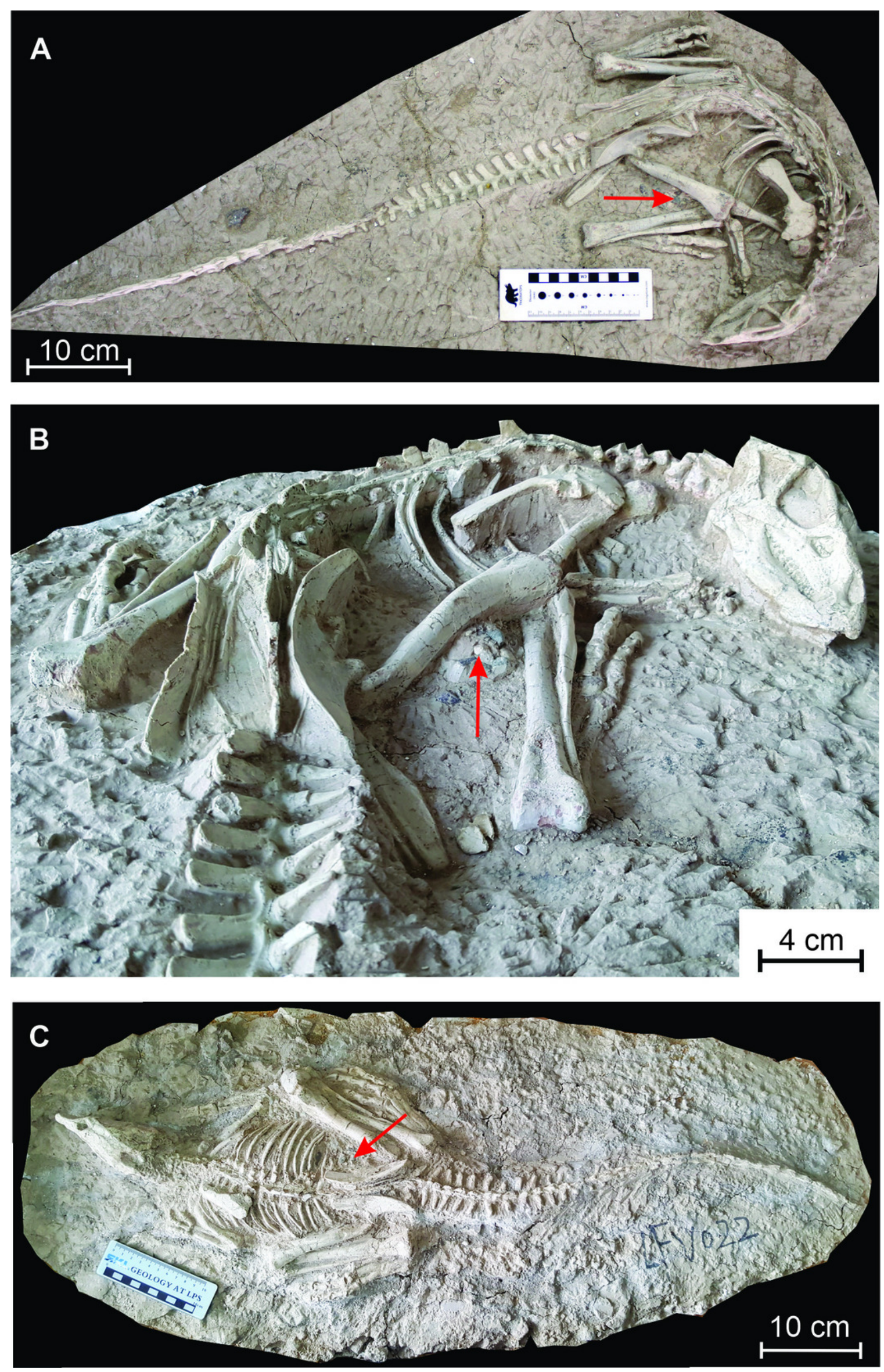
Figure 2

Skull of PMOL AD00114 in right lateral view.

(A) photograph; (B) line drawing. 

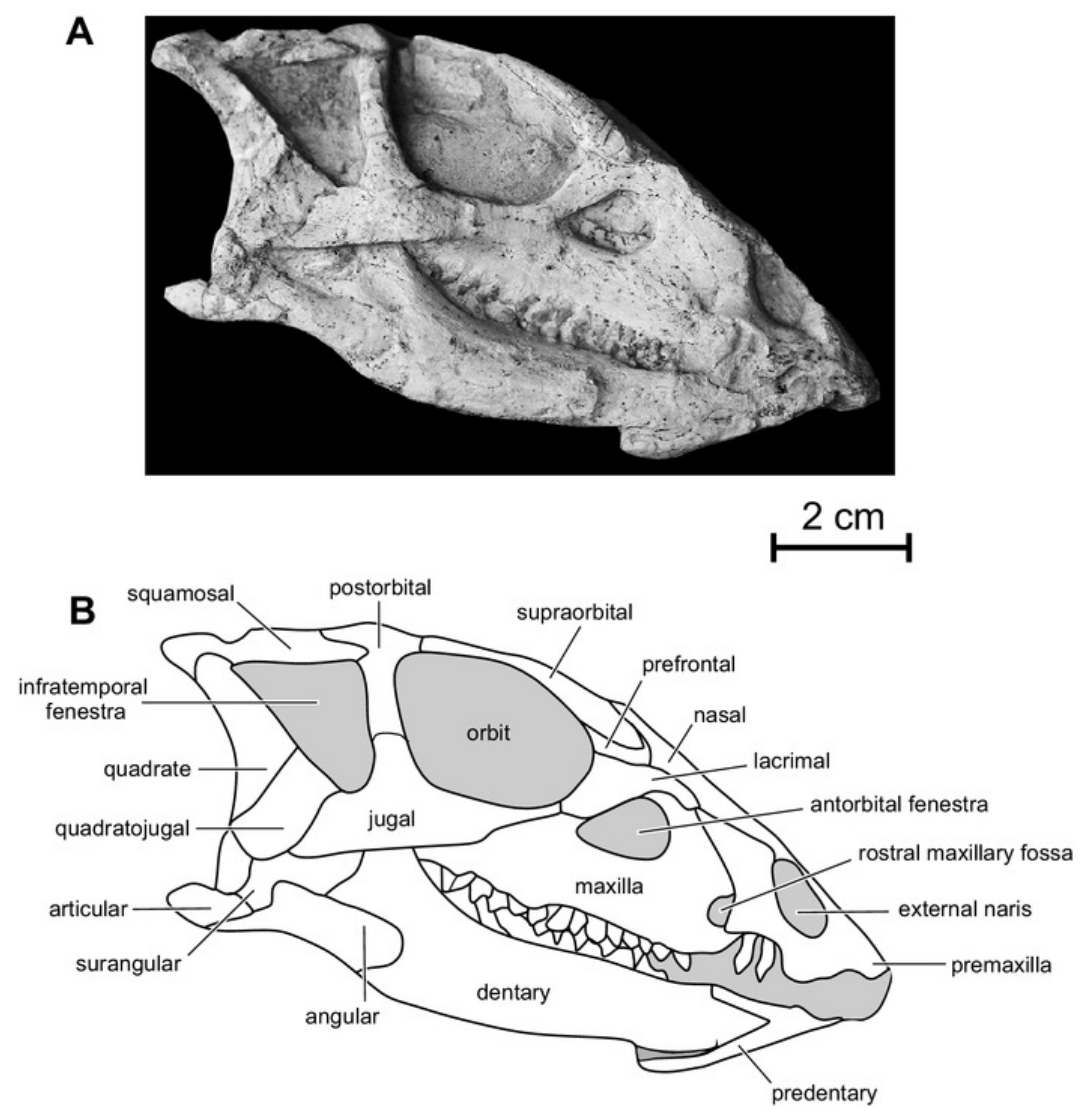

Peer) reviewing PDF | (2020:05:48592:1:1:NEW 31 Jul 2020) 
Figure 3

Skull of PMOL AD00114 in left dorsolateral view.

(A) photograph; (B) line drawing. 

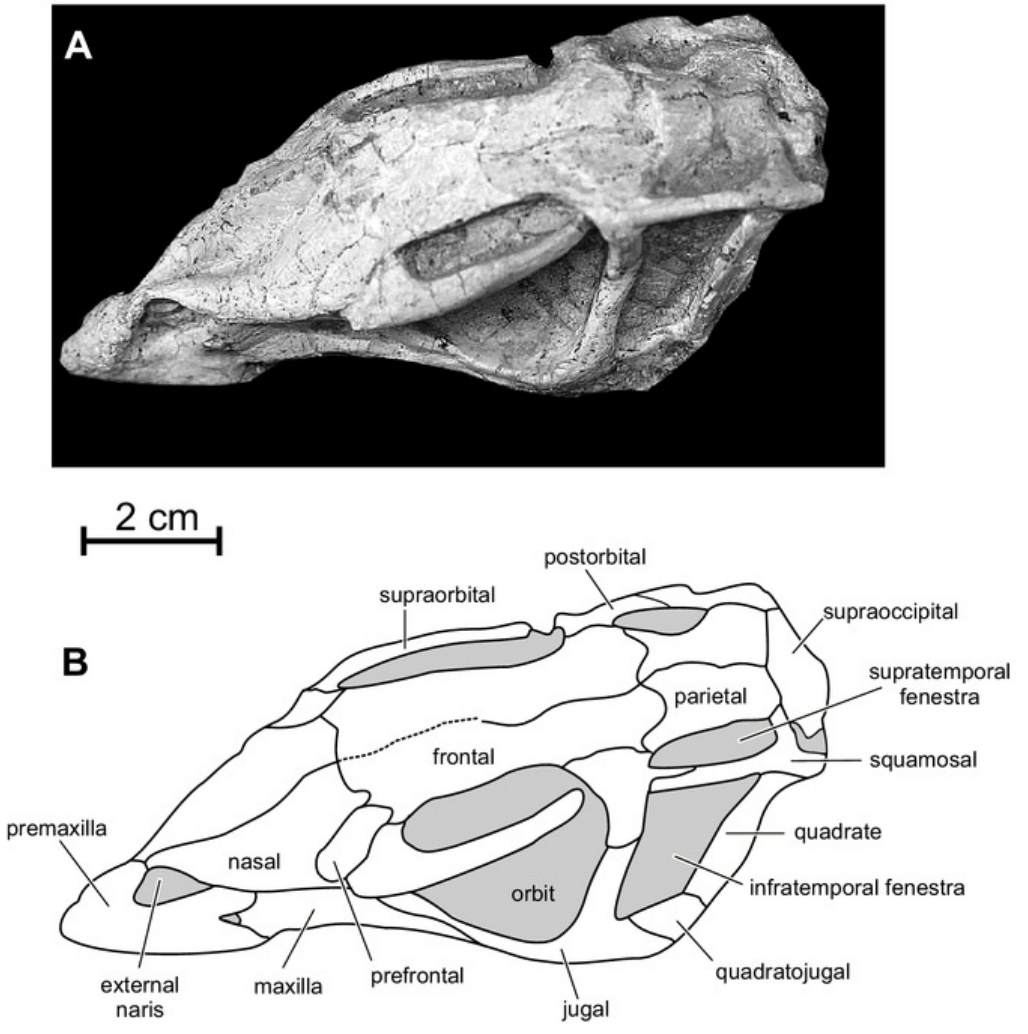

PeerJ reviewing PDF | (2020:05:48592:1:1:NEW 31 Jul 2020) 
Figure 4

Skull of PMOL AD00114 in dorsal view.

(A) photograph; (B) line drawing. 


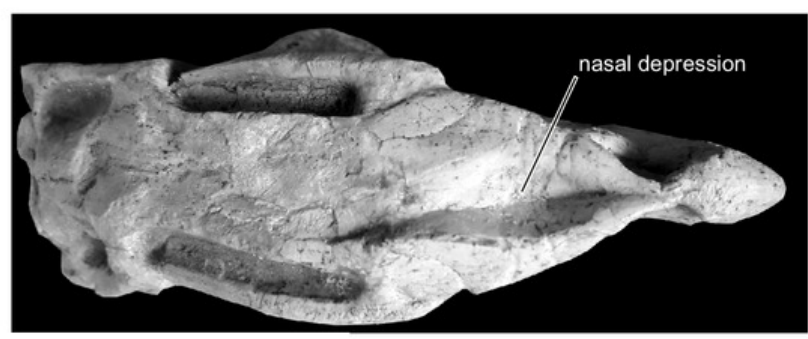

A

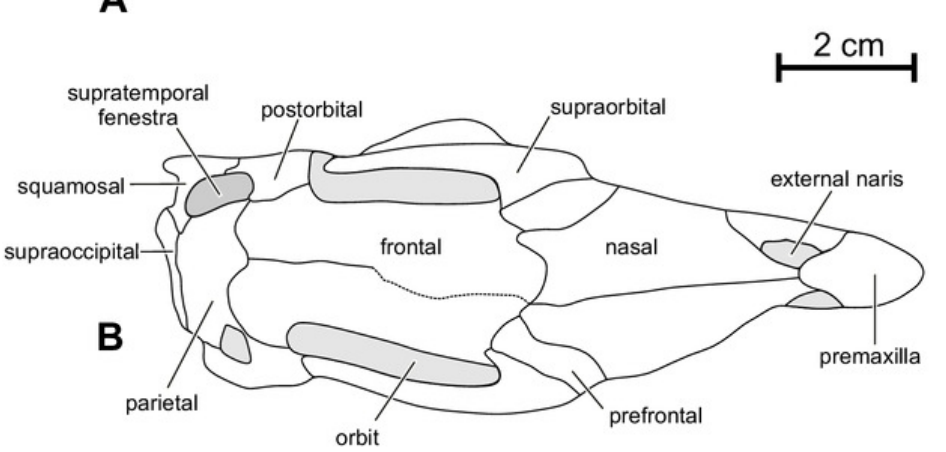

Peer) reviewing PDF | (2020:05:48592:1:1:NEW 31 Jul 2020) 
Figure 5

Skull of PMOL AD00114 in right lateral view.

(A) close-up of the premaxillary region; (B) close-up of the maxillary region; (C) close-up of the maxillary teeth. 

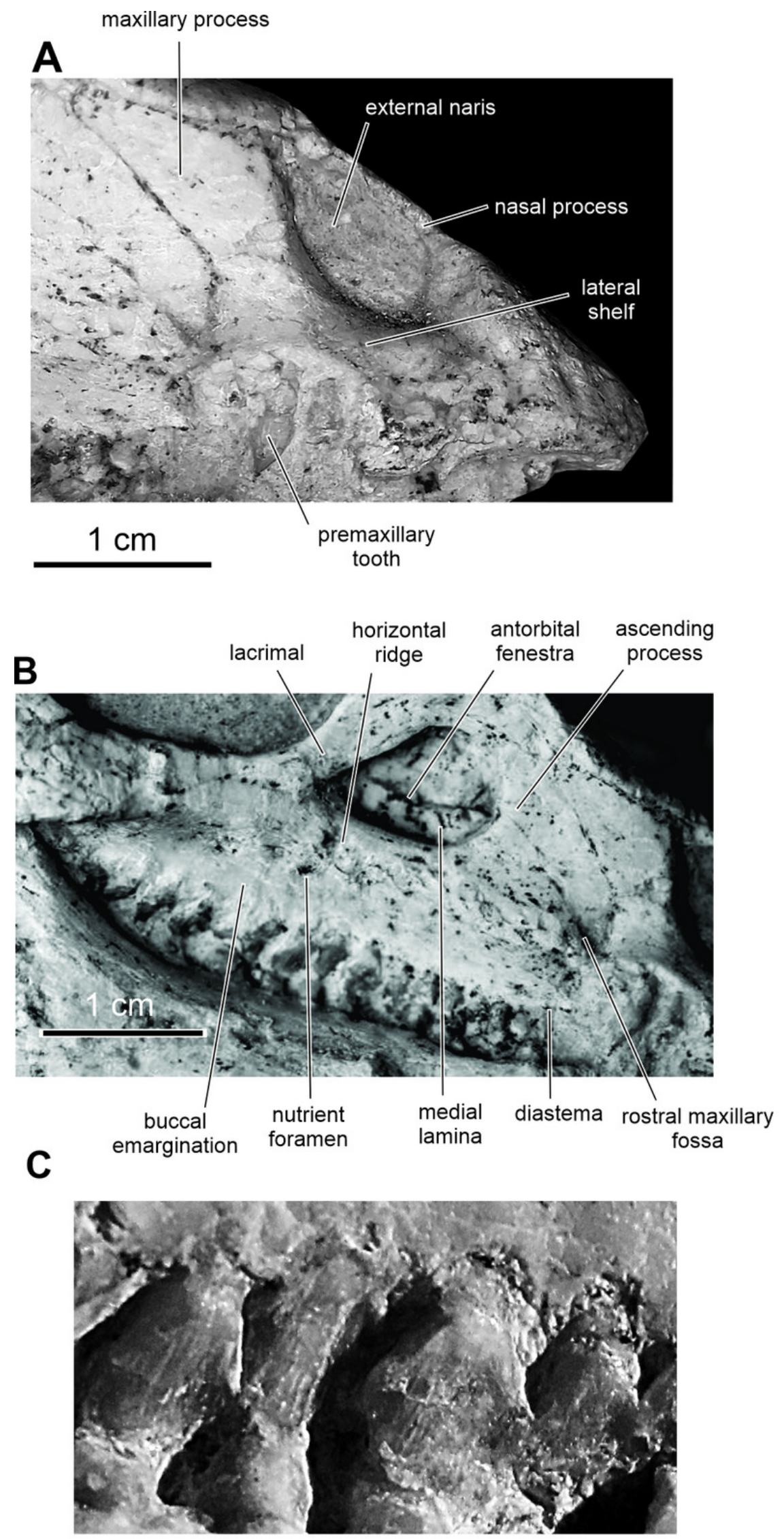

\section{$3 \mathrm{~mm}$}

PeerJ reviewing PDF | (2020:05:48592:1:1:NEW 31 Jul 2020) 
Figure 6

Skull of PMOL AD00114.

(A) antorbital fenestra region in right lateral view; (B) left squamosal and postorbital in dorsolateral view; (C) caudal half of the skull in right lateral view. 


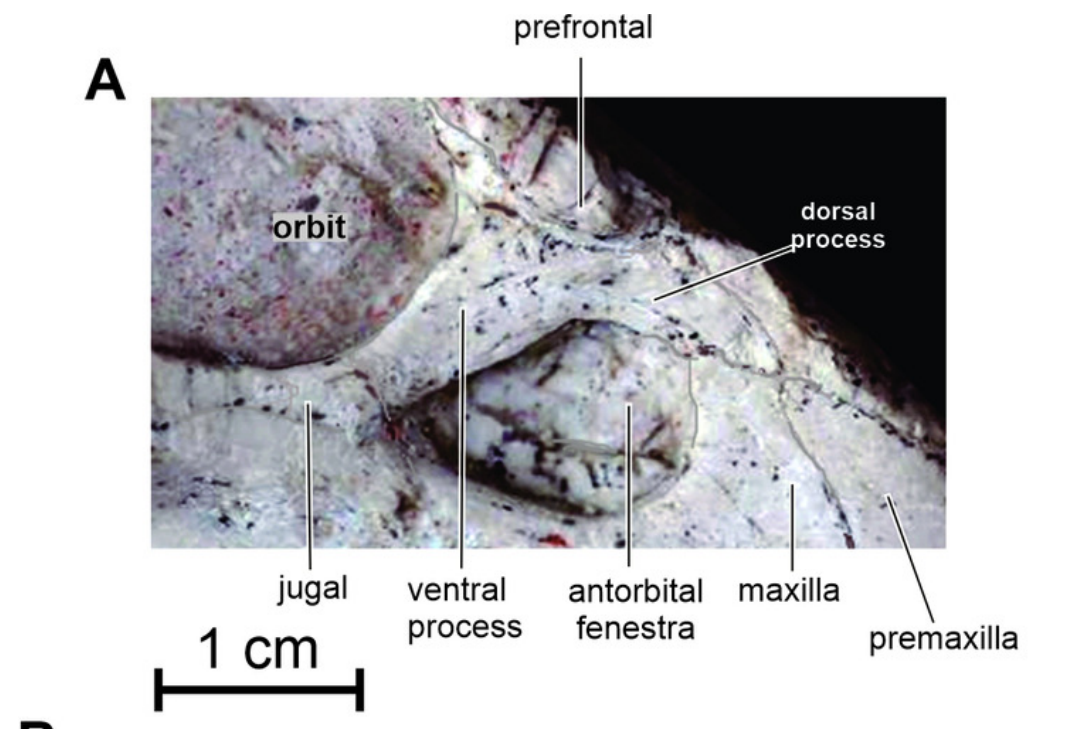

B
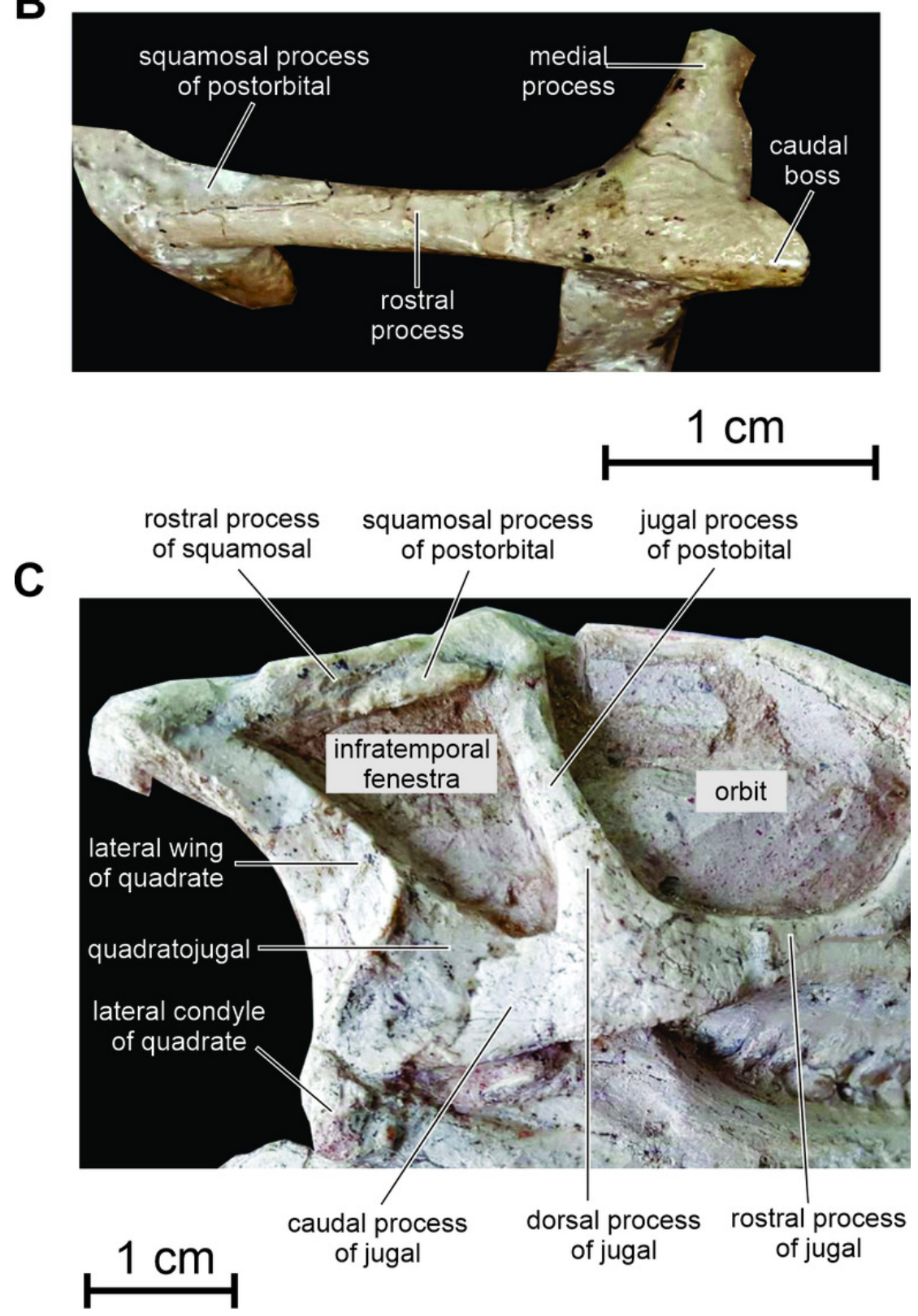

PeerJ reviewing PDF | (2020:05:48592:1:1:NEW 31 Jul 2020) 
Figure 7

Postdentary bones of JMOL AD00114 in right lateral view.

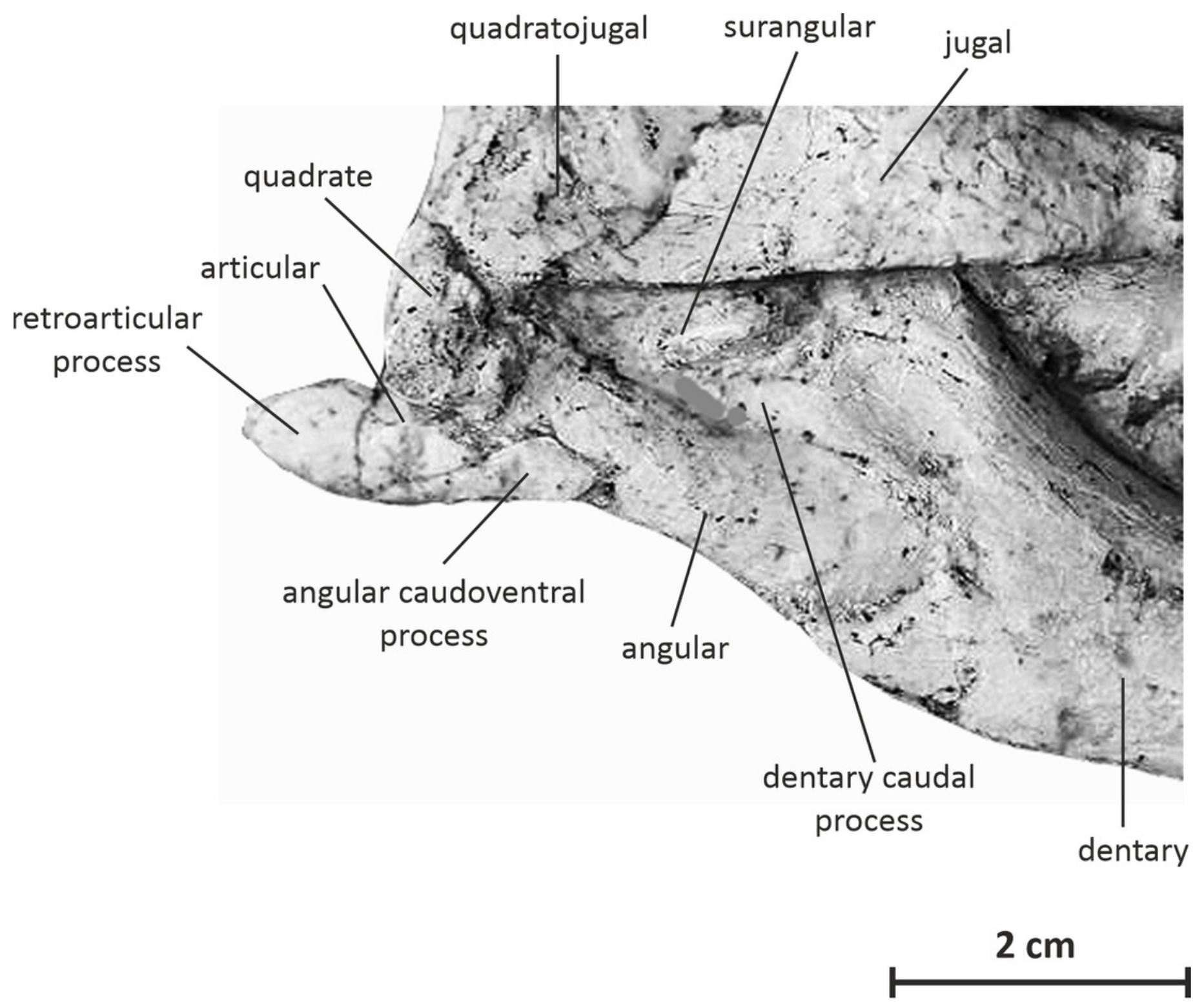


Figure 8

Axial skeleton of Changmiania liaoningensis.

(A) cervical vertebrae 2 to 4 of PMOL AD00114 in right lateral view; (B) cervical and dorsal series of PMOL AD00114 in left lateral view; (C) neck region of PMOL LFV022 in right dorsolateral view. Abbreviations: cv: cervical vertebra; d: dorsal vertebra. 


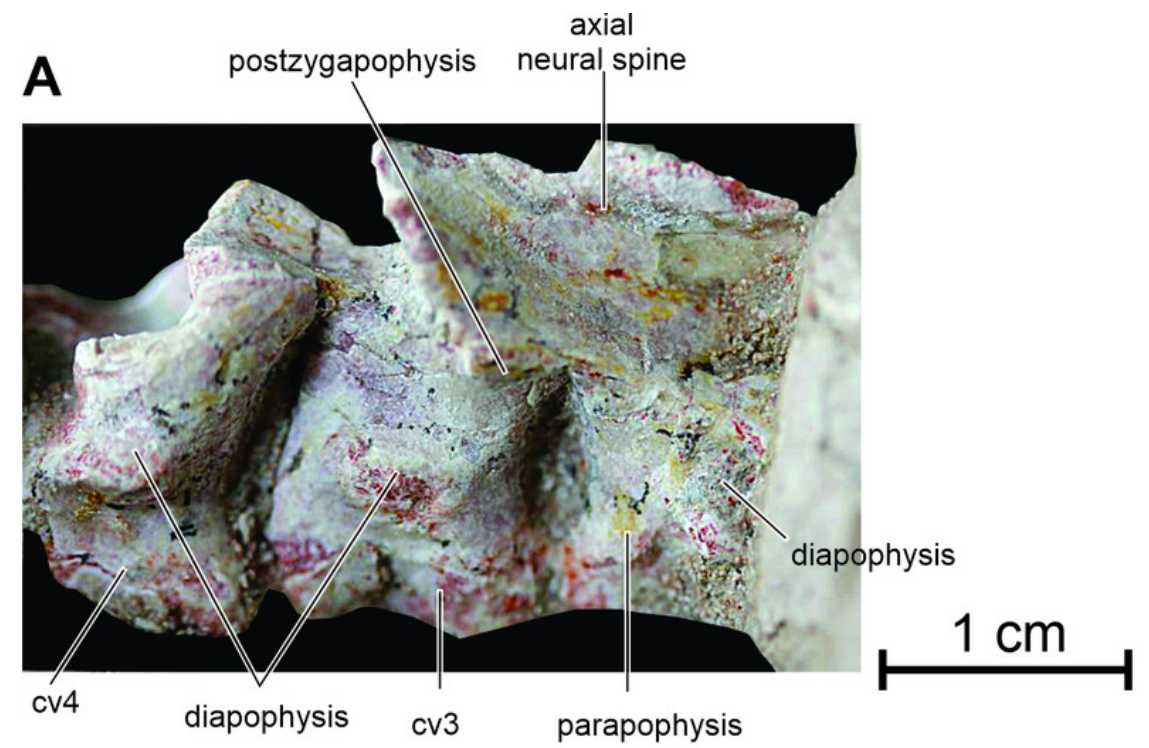

B
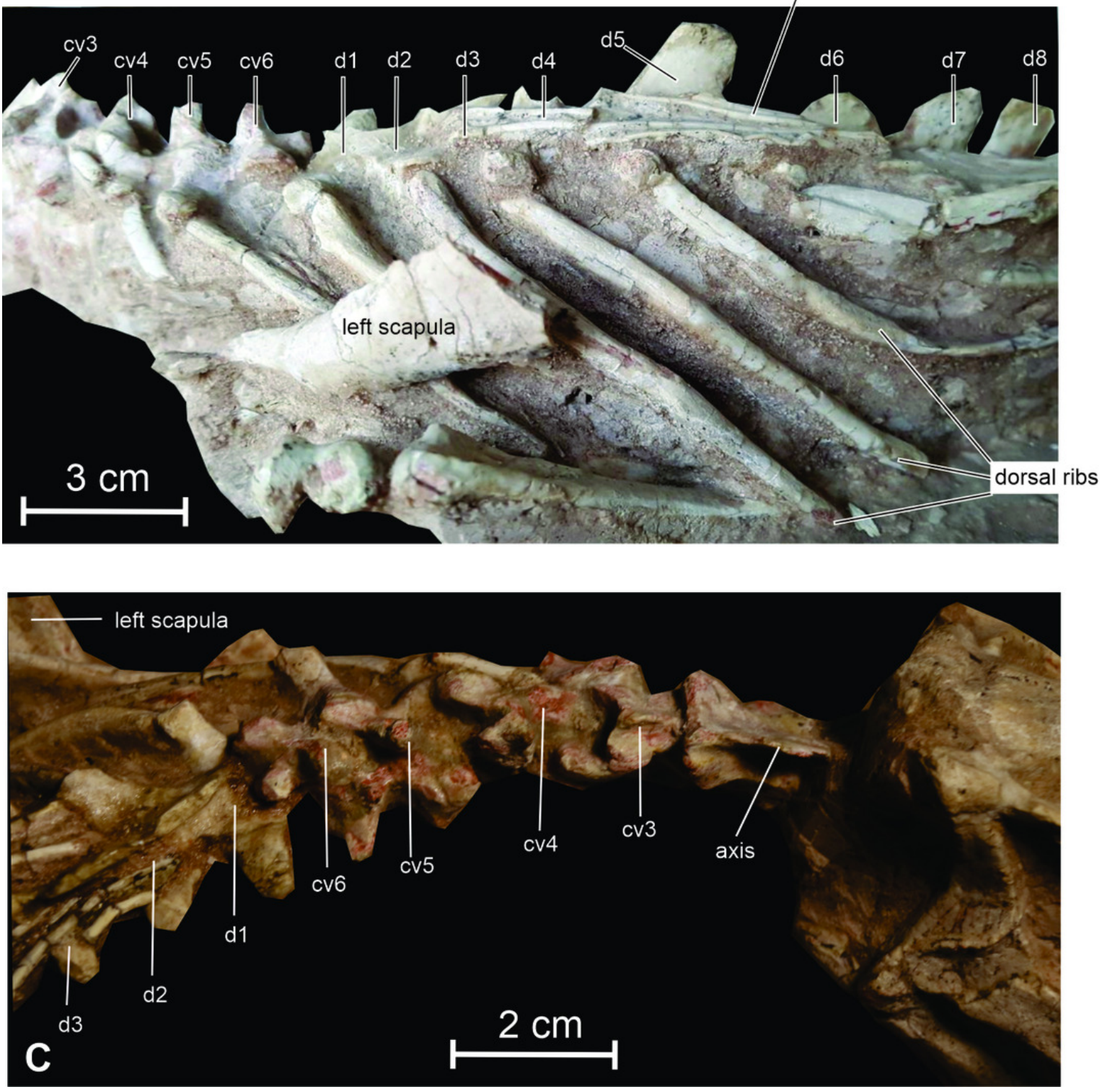

Peer) reviewing PDF | (2020:05:48592:1:1:NEW 31 Jul 2020) 
Figure 9

Axial skeleton of PMOL AD00114.

(A) sacrum and proximal caudal vertebrae in dorsal view; (B) proximal caudal vertebrae in right lateral view; $(C)$ distal caudal vertebrae in left lateral view. Abbreviation: ca: caudal vertebra. 

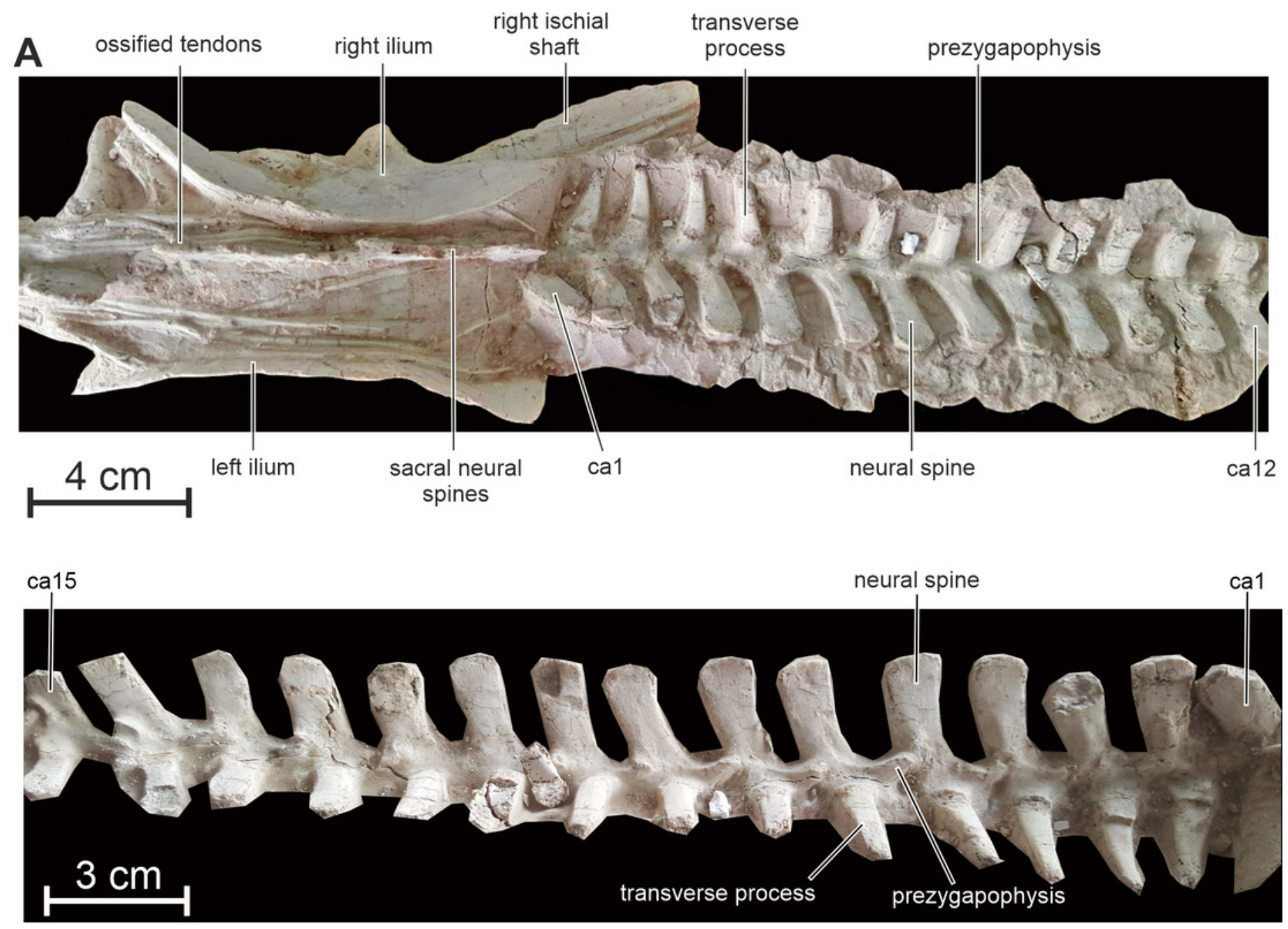

B

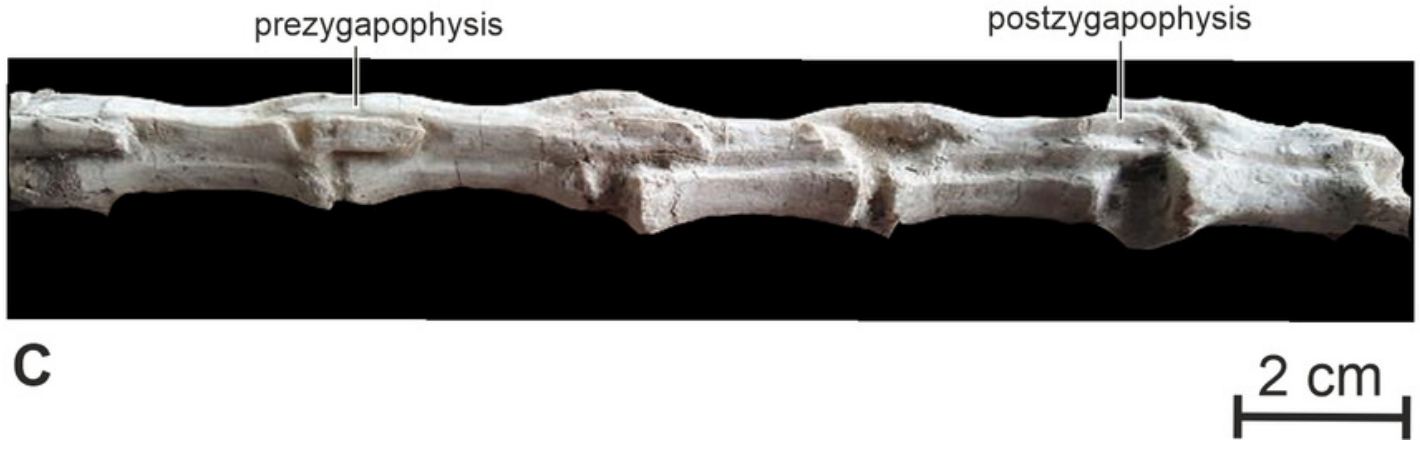




\section{Figure 10}

Scapular girdle and forelimb of Changmiania liaoningensis.

(A) photograph and (B) line drawing of the right scapular girdle and forelimb of PMOL AD00114; (C) detail of the right scapulocoracoid of PMOL AD00114 in lateral view; D: left forelimb of PMOL LFV022 in dorsal view. Abbreviation: mc: metacarpal. 


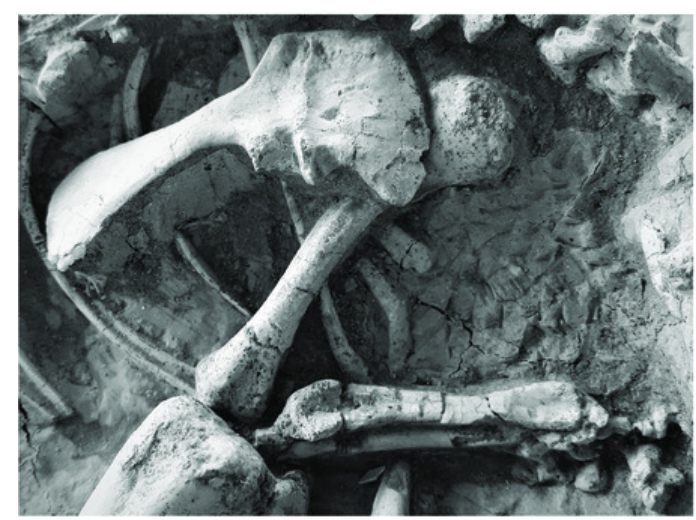

A
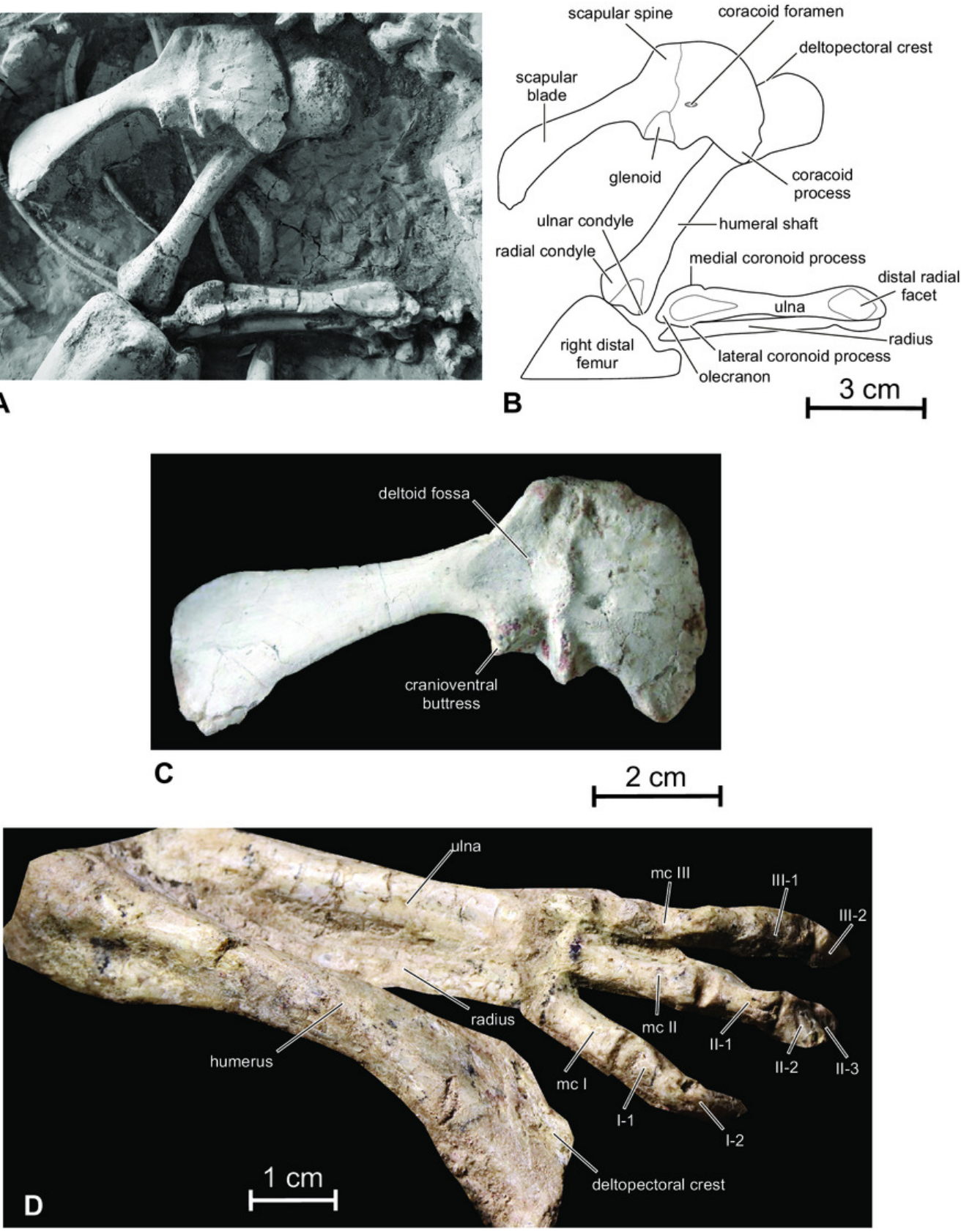

Peer) reviewing PDF | (2020:05:48592:1:1:NEW 31 Jul 2020) 


\section{Figure 11}

Pelvic girdle and hindlimbs of PMOL AD00114.

(A) right ilium in lateral view; (B) photograph of distal ischia and right hindlimb; (C) line drawing of distal ischia and right hindlimb; (D) left foot in dorsal view; (E) gastroliths. 

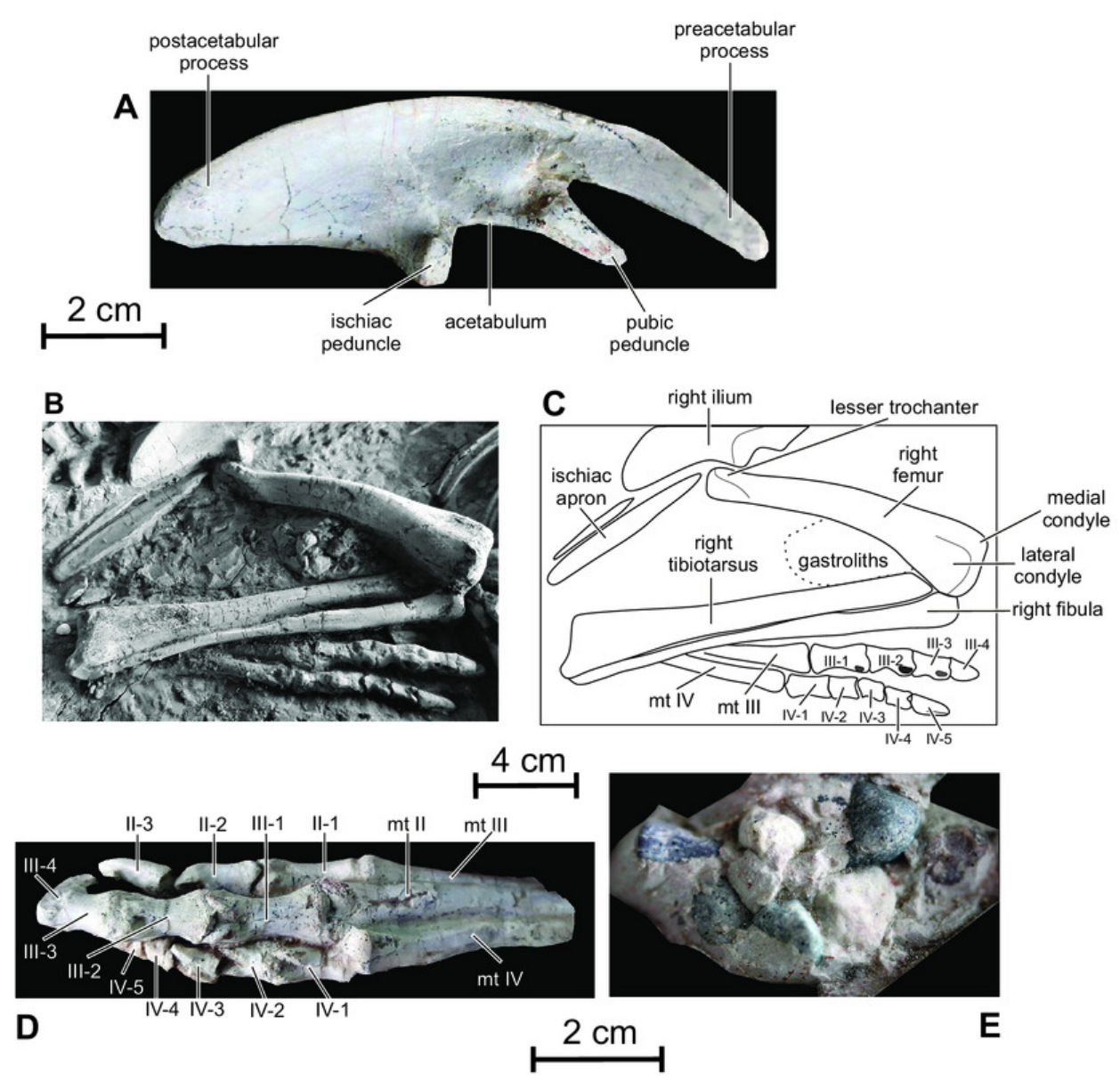

Peer) reviewing PDF | (2020:05:48592:1:1:NEW 31 Jul 2020) 


\section{Figure 12}

Phylogenetic position of Changmiania liaoningensis gen. et sp. nov. among Ornithischia.

Strict consensus tree of 49 MPT's. Tree Length $=859$. Nodal support (Bremer indices $>1$ ) is indicated above or below the branches. 


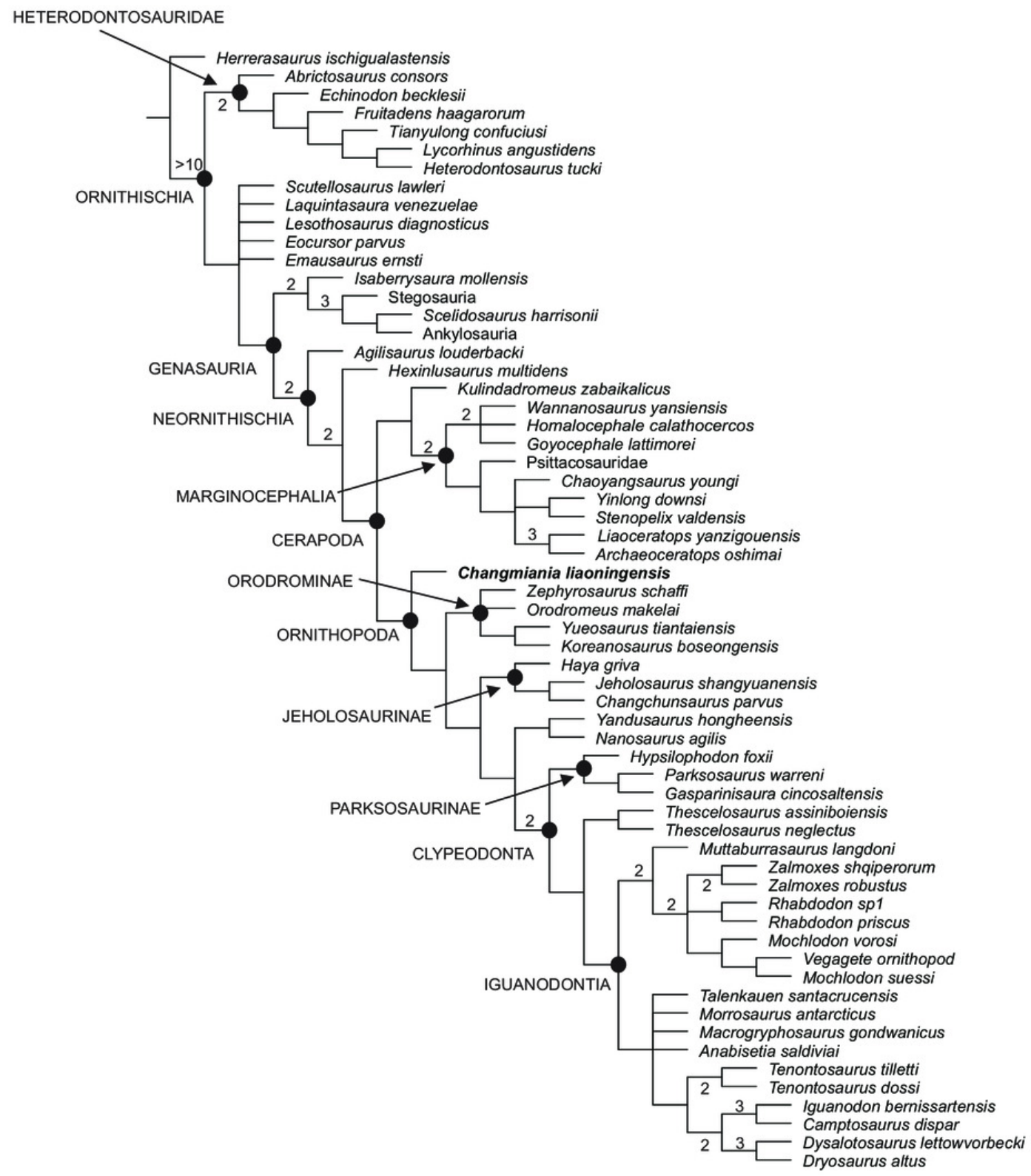




\section{Figure 13}

Phylogenetic position of Changmiania liaoningensis gen. et sp. nov. among Ornithischia. Fully-resolved agreement subtree obtained after the exclusion of 5 unstable 'wilcard' taxa, carried out using the 'Comparisons-Agreement subtree(s)' option of TN

Fully-resolved agreement subtree obtained after the exclusion of 5 unstable 'wilcard' taxa, carried out using the 'Comparisons-Agreement subtree(s)' option of TNT (Goloboff et al., 2008) 


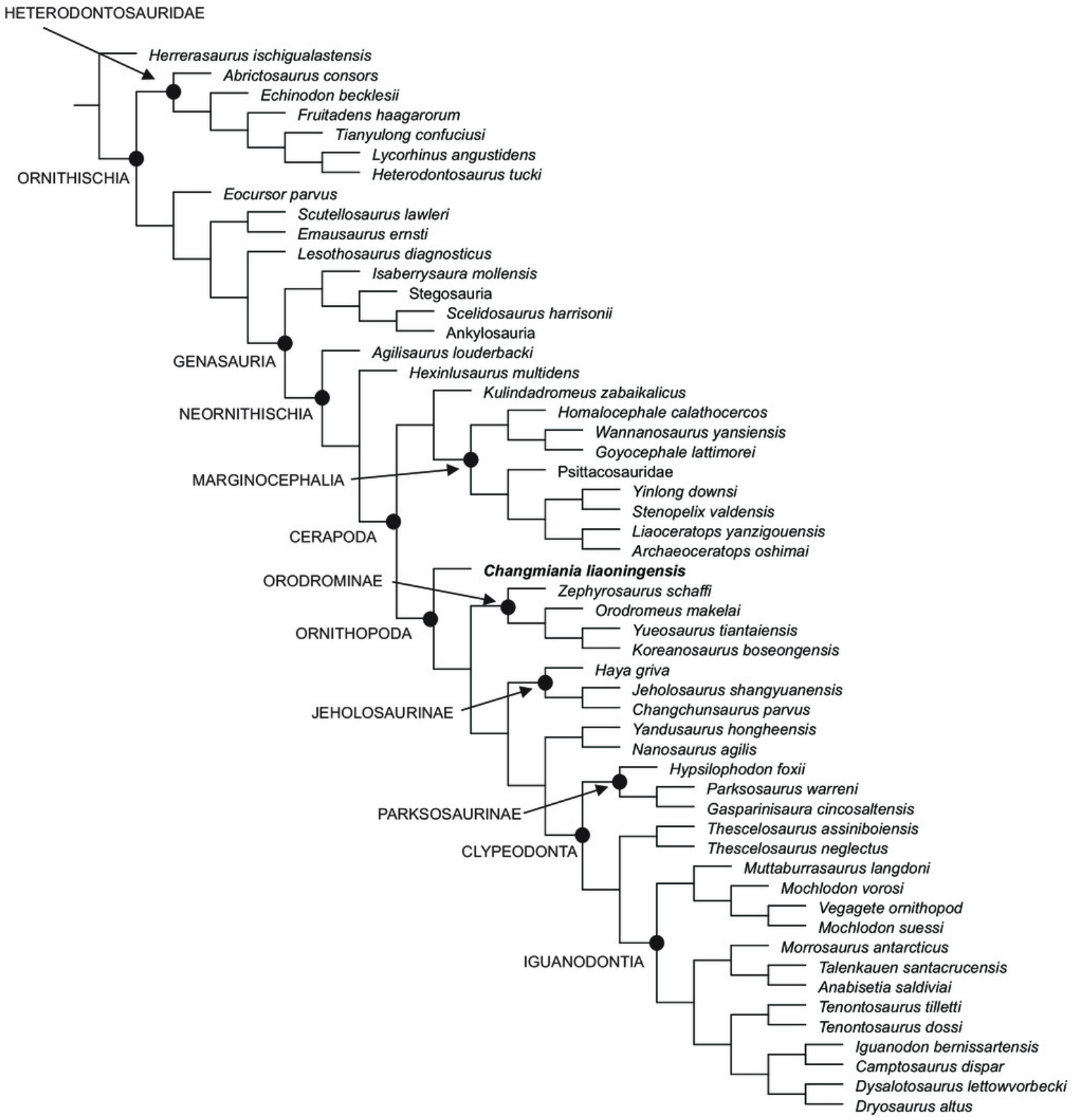




\section{Table 1 (on next page)}

Selected measurements of Changmiania liaoningensis PMOL AD00114 specimen. 
Total length:

Skull, length:

maximum height of skull:

Orbit length:

Snout length:

External antorbital fenestra length:

External naris length:

Supratemporal fenestra length:

Infratemporal fenestra, rostrocaudal length of dorsal margin: height:

Mandible length:

Dentary, length:

height of dentary at mid-length:

Tail total length:

Scapula, length:

height of proximal head:

minimum height of blade:

Humerus, length: minimum mediolateral width:

Ulna, length: mediolateral width of proximal end: mesiolateral width of distal end:

Ilium, length: length of preacetabular process: length of postacetabular process:

Femur length:

Tibotarsus length:

Fibula length:

Individual pes element lengths:

Mt I: ? Mt II: ? Mt III: $67 \mathrm{~mm}$ Mt IV: $60 \mathrm{~mm}$

I-1:? I-2: ?

II-1: $19 \mathrm{~mm}$

II-2: $15.2 \mathrm{~mm}$

III-2: $15.6 \mathrm{~mm}$

IV-2: $12 \mathrm{~mm}$
II-3: $18.4 \mathrm{~mm}$

III-3: $15 \mathrm{~mm} \quad$ III-4: $>20 \mathrm{~mm}$

IV-3: $10.6 \mathrm{~mm} \quad$ IV-4: $10 \mathrm{~mm}$
$1170 \mathrm{~mm}$

$110.5 \mathrm{~mm}$

$37.4 \mathrm{~mm}$

$30 \mathrm{~mm}$

$52 \mathrm{~mm}$

$13 \mathrm{~mm}$

$11 \mathrm{~mm}$

$17 \mathrm{~mm}$

$18 \mathrm{~mm}$

$20 \mathrm{~mm}$

$93 \mathrm{~mm}$

$52 \mathrm{~mm}$

$13.5 \mathrm{~mm}$

$650 \mathrm{~mm}$

$68 \mathrm{~mm}$

$27 \mathrm{~mm}$

$11 \mathrm{~mm}$

$85 \mathrm{~mm}$

$8 \mathrm{~mm}$

$60 \mathrm{~mm}$

$11.3 \mathrm{~mm}$

$9.3 \mathrm{~mm}$

$101.5 \mathrm{~mm}$

$42 \mathrm{~mm}$

$36 \mathrm{~mm}$

$115.5 \mathrm{~mm}$

$140 \mathrm{~mm}$

$130 \mathrm{~mm}$

IV-5: $17.8 \mathrm{~mm}$ 


\section{Table 2 (on next page)}

Comparisons of postcranial measurements (in $\mathrm{mm}$ ) in selected basal ornithopods:

Changmiania liaoningensis, Dryosaurus altus, Koreanosaurus boseongensis, Haya griva, Hypsilophodon foxii, Jeholosaurus shangyuanensis, Nanosaurus agilis, Orodromeus makelai, and Oryctodromeus cubicularis. 
1

\begin{tabular}{|l|l|c|c|c|c|c|}
\hline \multicolumn{1}{|c|}{ Taxon } & \multicolumn{1}{|c|}{ Ref } & $\begin{array}{c}\text { Humerus } \\
\text { length }\end{array}$ & $\begin{array}{c}\text { Femur } \\
\text { length }\end{array}$ & $\begin{array}{c}\text { Tibia } \\
\text { length }\end{array}$ & H/F & T/F \\
\hline C. liaoningensis & JMOL AD00114 & 85 & 115.5 & 140 & 0.74 & 1.21 \\
K. boseongensis & KDRC-BB & $205-215$ & 196.5 & 204 & $>1$ & 1.04 \\
H. foxii & NHMUK R5829 & 159 & 198 & 238 & 0.8 & 1.20 \\
H. foxii & NHMUK R5830 & 74 & 101 & 117 & 0.74 & 1.16 \\
O. makelai & MOR 294 & 72 & 106 & 132 & 0.68 & 1.25 \\
O. cubicularis & MOR 1636 & 157 & - & 254 & - & - \\
J. shangyuanensis & IVPP V12542 & 61.5 & 94.4 & 113.4 & 0.65 & 1.20 \\
H. griva & IGM 100/2015 & 86 & 131 & 155 & 0.66 & 1.18 \\
N. agilis & BYU ESM-163R & 104 & 151 & 180 & 0.69 & 1.19 \\
D. altus & YPM 1876 & 190 & 360 & 395 & 0.53 & 1.1 \\
\hline
\end{tabular}

2 